NBER WORKING PAPER SERIES

CHINESE BOND MARKET AND INTERBANK MARKET

\author{
Marlene Amstad \\ Zhiguo He \\ Working Paper 25549 \\ http://www.nber.org/papers/w25549 \\ NATIONAL BUREAU OF ECONOMIC RESEARCH \\ 1050 Massachusetts Avenue \\ Cambridge, MA 02138 \\ February 2019
}

\begin{abstract}
Amstad: The Chinese University of Hong Kong, Shenzhen and Shenzhen Finance Institute Email: marleneamstad@cuhk.edu.cn (www. marleneamstad.net). Zhiguo He: University of Chicago, Booth School of Business, and NBER; Tsinghua University, School of Economics and Management. Email: zhiguo.he@chicagobooth.edu, website: www.zhiguohe.com. We thank Tianshu Lyu (Research Professional at Fama-Miller Center) for his excellent research assistance in preparing this chapter, Chang Ge for assistance to Section 5, Andrew Levin who contributed to Section 6.3, and Zhuo Chen (Tsinghua University), Kai Guo (People's Bank of China), Jinyu Liu (University of International Business and Economics), and Rengming Xie (CITIC, China) for many useful comments and discussions. Zhiguo He acknowledges the financial support from China Initiative at Macro Financial Research program at University of Chicago. The views expressed herein are those of the authors and do not necessarily reflect the views of the National Bureau of Economic Research.
\end{abstract}

NBER working papers are circulated for discussion and comment purposes. They have not been peer-reviewed or been subject to the review by the NBER Board of Directors that accompanies official NBER publications.

(C) 2019 by Marlene Amstad and Zhiguo He. All rights reserved. Short sections of text, not to exceed two paragraphs, may be quoted without explicit permission provided that full credit, including $(\odot$ notice, is given to the source. 
Chinese Bond Market and Interbank Market

Marlene Amstad and Zhiguo He

NBER Working Paper No. 25549

February 2019

JEL No. F4,G2,O16,O2,O53

\begin{abstract}
$\underline{\text { ABSTRACT }}$
Over the past twenty years, especially the past decade, China has taken enormous strides to develop its bond market as an integral step of financial reform. This paper aims to provide the most up-to-date overview of Chinese bond markets, by highlighting two distinct and largely segmented markets: Over-the-Counter based interbank market, and centralized exchange market. We explain various bond instruments traded in these two markets, highlighting their inherent connection with the banking system, and many multi-layer regulatory bodies who are interacting with each other in an intricate way. We also covers the credit ratings and rating agencies in Chinese market, and offer an account of ever-rising default incidents in China starting 2014. Finally, we discuss the recent regulatory tightening of shadow banking since late 2017 and its impact on bond investors, and the forces behind the internalization of Chinese bond markets in the near future.
\end{abstract}

Marlene Amstad

Chinese University of Hong Kong, Shenzhen

marleneamstad@cuhk.edu.cn

Zhiguo He

University of Chicago

Booth School of Business

5807 S. Woodlawn Avenue

Chicago, IL 60637

and NBER

zhiguo.he@chicagobooth.edu 


\title{
Chinese Bond Market and Interbank Market ${ }^{1}$
}

\author{
Marlene AMSTAD and Zhiguo HE
}

\section{Contents}

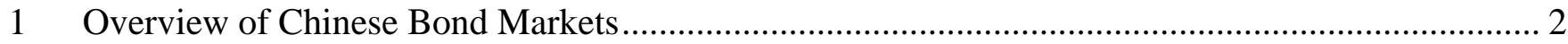

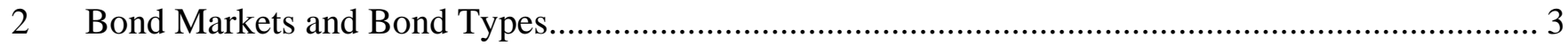

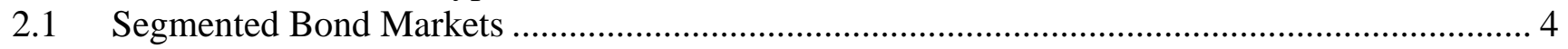

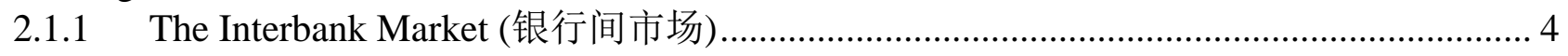

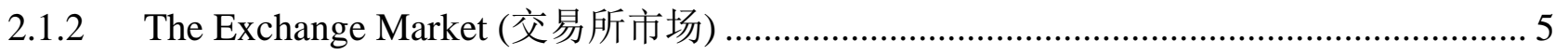

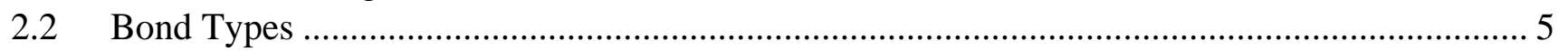

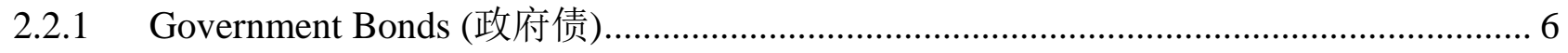

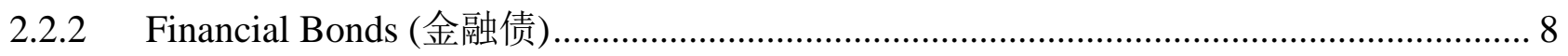

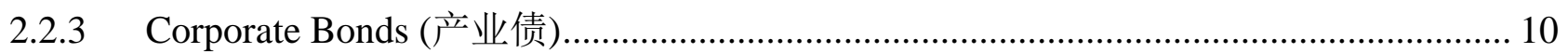

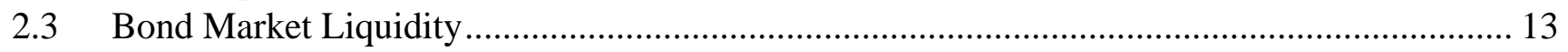

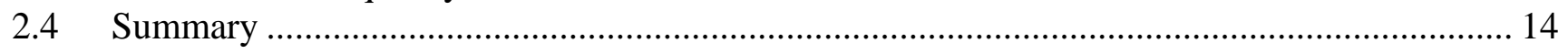

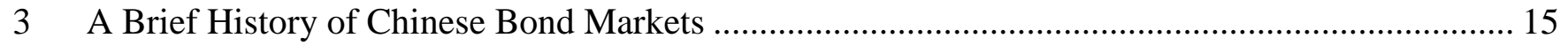

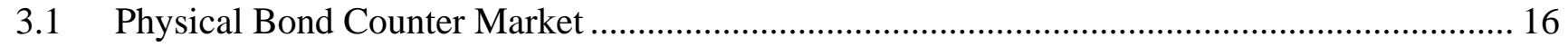

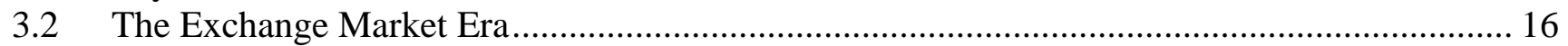

3.3 The Rise of Interbank Market .................................................................................... 17

3.4 Bond Markets and the Growth of Chinese Economy ........................................................ 18

$4 \quad$ Issues and Recent Trends of Chinese Bond Markets.............................................................. 19

4.1 Interest Rate Determination and Monetary Policy Transmission .......................................... 19

4.2 The Role of Banks and Shadow Banking.................................................................... 21

4.3 Regulatory Tightening Starting 2017 ......................................................................... 24

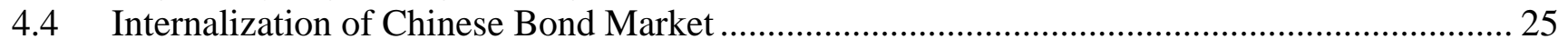

${ }^{1}$ This paper is written for the Handbook on Chinese Financial System, edited by Marlene Amstad, Guofeng Sun and Wei Xiong. Amstad: The Chinese University of Hong Kong, Shenzhen and Shenzhen Finance Institute and ABFER; Email: marleneamstad@cuhk.edu.cn (www.marleneamstad.net). Zhiguo He: University of Chicago, Booth School of Business, and NBER; Tsinghua University, School of Economics and Management. Email: zhiguo.he@chicagobooth.edu, website: www.zhiguohe.com. We thank Tianshu Lyu (Research Professional at the Fama-Miller Center) for his excellent research assistance in preparing this chapter, Chang Ge for assistance to Section 5, Andrew Levin who contributed to Section 6.3, and Zhuo Chen (Tsinghua University), Kai Guo (People’s Bank of China), Jinyu Liu (University of International Business and Economics), and Rengming Xie (CITIC, China) for many useful comments and discussions. Zhiguo He acknowledges the financial support from China Initiative at Macro Financial Research program at University of Chicago. 


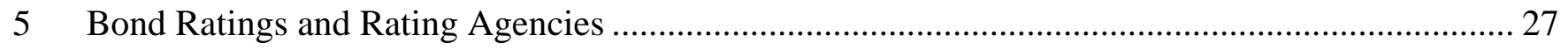

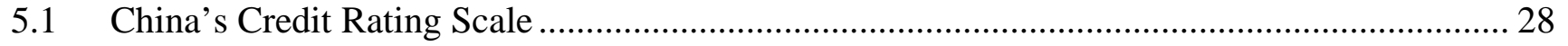

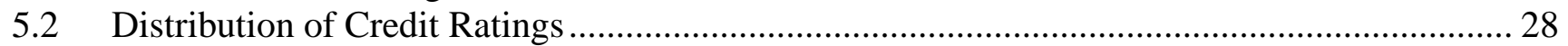

5.3 Low Default Rate, Implicit Guarantees and Rating Migration ..................................................... 29

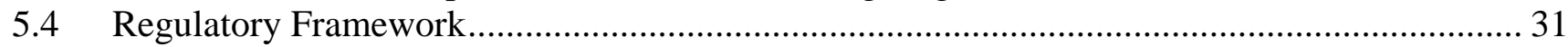

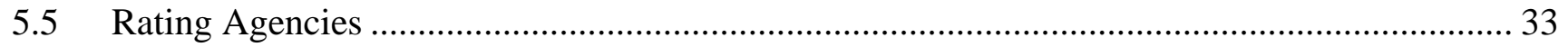

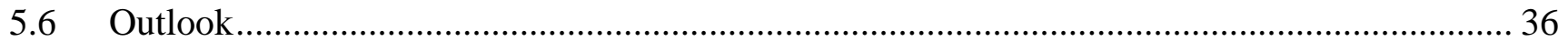

$6 \quad$ Credit Spreads and Default in Chinese Bond Market........................................................................ 37

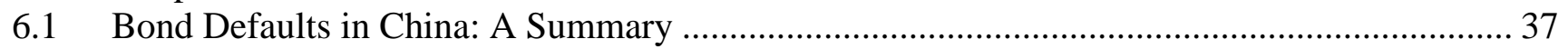

6.2 Defaults, Bond Ratings, and Credit Spreads ............................................................................. 38

6.3 Bond Default Cases, Bankruptcy, and Post-default Recovery ..................................................... 39

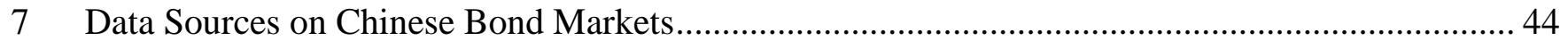

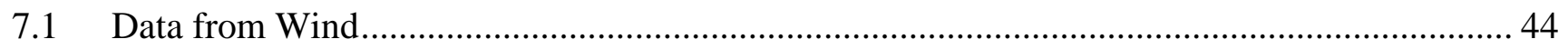

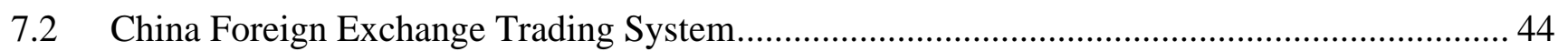

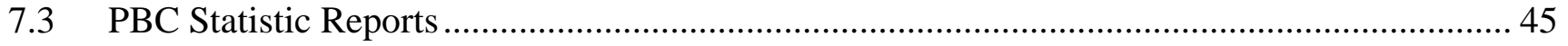

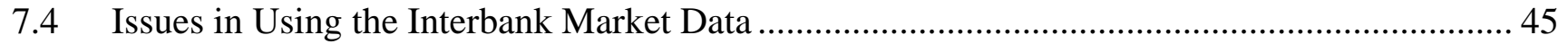

\section{Overview of Chinese Bond Markets}

Over the past twenty years, especially the past decade, China has taken enormous strides to develop its bond market as an integral step of financial reform, along with its tremendous effort in interest rate liberalization and internalization of its currency RMB.

Figure 1 Panel A depicts the growth of Chinese bond market capitalization scaled by GDP in the past decade; we observe that bond market capitalization over GDP rises from 35\% in 2008 to more than $90 \%$ in 2017. For comparison, the bond market capitalization over GDP in U.S. stays slightly above $200 \%$ during the same time period. Relative to the stock market capitalization, Chinese bond market has been also experiencing a steady uprising trend, only to catch up to the U.S. level which is about $130 \%$ in 2017. Due to historical reasons, there are two distinct and largely segmented markets in today's Chinese bond markets: Over-the-Counter based interbank market, and centralized exchange market. The interbank bond market in China resembles the interbank market observed in developed countries like U.S., while the exchange bond market in China is part of the Stock Exchanges in Shanghai and Shenzhen. Section 4.2 
offers a brief history of the development and evolution of these two bond markets. The interbank market is the dominant one within these two markets; at the end of 2018 , about $89 \%$ of the total bonds outstanding in China are in the interbank market, while the rest of $11 \%$ is in the exchange. ${ }^{2}$ Various fixed income securities are issued and traded on these two bond markets, with many multi-layer regulatory bodies interacting with each other in an intricate way.

We first elaborate on the above mentioned two bond markets in Section 2, together with various bond instruments traded there. Section 3 provides a brief history of Chinese bond markets, and Section 4 highlights their inherent connection with and the banking system, together with the internalization of Chinese bond markets in the near future. Section 5 covers the credit ratings and rating agencies, and Section 6 offers an account of ever-rising default incidents in China starting 2014. We provide some data sources for in-depth study of Chinese bond market in Section 7.

\section{Bond Markets and Bond Types}

In this section, we first go over the details of the two segmented Chinese bond markets, i.e., the interbank market and the exchange market. After explaining the various bond security types traded in Chinese bond markets, we provide a comparison between these two bond markets.

\footnotetext{
${ }^{2}$ Besides these two major bond markets, there is also a Counter Trading System through which retail investors trade bonds with commercial banks at their bank counters. This retail Over-the-Counter market can be considered as the natural extension of the interbank market.
} 


\subsection{Segmented Bond Markets}

\subsubsection{The Interbank Market (银行间市场)}

The interbank bond market, often called as the China Interbank Market (CIBM, 中国银行间债券市场), was established in 1997 and has become the dominating market for bond issuance and trading in China. Beside spot and repurchase transactions, swaps and futures are also actively trade by participants in the interbank market. The value of outstanding bonds in the interbank market reached 76 trillion RMB at the end of 2018, with an annual issuance of 41 trillion RMB in the same year.

As a wholesale market, the participants of interbank market are restricted to various qualified institutional investors including commercial banks, mutual funds, insurance companies, and security firms. As shown in Figure 2, commercial banks (e.g., state-owned commercial banks, join-stock commercial banks, urban and rural credit unions, etc.) form the largest group of institutional investors who held about $57 \%$ of the outstanding bonds in the interbank market in 2018. The second largest group is mutual funds, broadly defined to include the fast-growing asset management industry thanks to the rise of wealth-management products after 2012; they held about $29 \%$ of outstanding bonds in the interbank market. Security firms, insurance companies, and foreign institutions are the next; these three groups of institutional investors formed a market share of $7 \%$ in the interbank market.

The main regulator of the interbank market is the People’s Bank of China (PBC, 中国人民银行), the central bank in China. Participants in the interbank market trade via China Foreign Exchange Trade System (CFETS, 外汇交易中心), and all participating institutions are required to open their accounts in China Central Depository \& Clearing Co. Ltd (CCDC, 中债登), a leading depository and clearing house in China. After the terms of trades are finalized through bilateral bargaining, CFETS record these transactions and CCDC offers exclusive custodial and clearing services in the interbank market. This 
monopolistic position came to an end after the establishment of Shanghai Clearing House (SHCH, 上清 所) on November 2009. Led by the PBC, SHCH competes with CCDC by offering clearing services for products like Medium-Term Notes, Commercial Papers, and Private Placement Notes.

\subsubsection{The Exchange Market (交易所市场)}

The exchange market for the Chinese bond market is part of the two Stock Exchanges located in Shanghai and Shenzhen, which were established around 1991 in the wake of State-Owned-Enterprise (SOE, 国有 企业) and financial reform. In August 1995, the exchange-based bond market was designated as the only legitimate bond market in China. This dominant position came to an end on May 1997 when the PBC, who worried about the overheated Chinese stock market fueled by bond repo financing, ordered all commercial banks to switch to the newly established interbank market on June 1997 (see Section 4.2 for more details). Despite this setback, the exchange market has been keeping its pace with the rapid growth of the ever-complicated Chinese financial system. At the end of 2018, the value of outstanding bonds in the exchange market reached 9.2 trillion RMB, with an annual issuance of 2.5 trillion RMB in 2018. The regulator of the exchange bond market is China Security Regulatory Commission (CSRC, 证监会), the powerful agency that is overseeing the Chinese stock markets. The participants of the exchange bond market include both institutional players and retail household investors, with only spot and repurchase transactions available. Electronic order books aggregate all bids from investors, and matched trades are settled via China Security Depository \& Clearing Co. Ltd (CSDC, 中证登).

\subsection{Bond Types}

We classify the fixed-income securities in Chinese bond market into three broad categories based on issuing entities: government bonds, financial bonds, and corporate bonds (that are issued by non-financial 
sectors). There is also another widely used classification among practitioners in China, which groups financial bonds and corporate bonds together as the so-called "Credit Bonds." Note that, in Chinese bond market, the issuers are still dominated by government or entities directly owned by the government (e.g., SOEs, most commercial banks, etc.)

Consistent with international practice, overall speaking, the creditworthiness of these bond instruments is decreasing in these three broad categories. Although corporate bonds in some international context also include long-term bonds issued by financial institutions, we specifically separate out bonds issued by financial institutions, given that almost all entities in Chinese financial sector are state-owned. Figure 3 compares the outstanding bonds in China and U.S. from 2008-2018, by these three categories. We observe relatively large fraction of government bonds (U.S. Treasury) in the U.S. bond market, but the weight of financial bonds and corporate bonds are similar.

We now turn to details of these bond types. Table 1 gives two snap shots of the outstanding balances of these bonds by types in Chinese bond markets in 2008 and 2018, and Table 2 gives the outstanding balance and issuance amount by bond types in 2018 .

\subsubsection{Government Bonds (政府债)}

\section{Treasury Bonds (国债)}

Treasury bonds are issued by the Ministry of Finance and backed by the fiscal revenue collected by the central government of China, representing the creditworthiness of China as a sovereign. There are mainly two types of Treasury bonds: book-entry treasury bonds that can be traded and transferred in the market, and certificate treasury bonds which cannot be traded and hence mainly used as a savings vehicle. As one of the key instruments by the PBC in implementing its monetary policy through open market operations, treasury bonds are one of the most important financial products in today's Chinese financial market, 
enjoying relatively large issuance and trading volumes with significant secondary market liquidity. At the end of 2018 the Treasury bonds reached 15 Trillion RMB, which is about $17 \%$ of the Chinese bond market. This is rather small relative to the importance of U.S. Treasuries in the U.S. bond market (46\%). Nowadays, a market mechanism via competitive bidding of participating financial institutions (mainly commercial banks) determine the interest rates offered by Treasury bonds. We will come back to this issue in Section 4.1.

\section{Municipal Bonds (地方政府债)}

Municipal bonds are issued by local governments in China. The market for municipal bonds almost did not exist until the 2009 four-trillion stimulus plan pushed out by Beijing in the wake of 2007/08 global financial crisis. The outstanding municipal bonds grew steadily but rather slowly in the next five years, only to observe a dramatic burst in its issuance volume in 2015. As explained later in Section 4.3, this is the outcome from a sequence of noticeable regulatory tightening from Beijing to reign in the ever-growing local government debt problem in the second half of 2014, especially the tone-setting guideline "Article 43.” As a result, in 2015 local governments issued 2.8 trillion RMB municipal bonds, of which 2 trillion is used to swap the debt initially raised by Local Government Financing Vehicles (LGFVs, 地方政府融 资平台).

At the end of 2018, the outstanding municipal bonds reached 18 trillion RMB, with a value-weighted average maturity of 6.4 years at issuance. Because municipal bonds are assigned to zero risk weights, most of municipal bonds in China are held by commercial banks (85\% at the end of 2018).

\section{Policy Bank Bonds (政策银行债)}

China has three policy banks today: China Development Bank, Export-Import Bank of China, and Agricultural Development Bank of China. They were established in 1994 to take over the governmentdirected lending functions from state-owned commercial banks, and are responsible for financing 
economic and trade development and state-invested projects. Policy bank bonds are issued by these three policy banks who are essentially backed by the central government, and hence considered to be quasisovereign bonds and risk-free (e.g., they receive zero risk-weight if held by commercial banks).

At the end of 2018, there were 14 trillion RMB policy bank bonds outstanding, which actually exceeds the Treasury bonds outstanding issued by Ministry of Finance. The weighted average of maturity at issuance is 8.1 years and two major institutional holders are national commercial banks and mutual funds. It is important to highlight that 55\% of policy bank bonds are issued by China Development Bank (CDB, 国家开发银行). Thanks to its depth and sheer size, the CDB bond has gained its superb secondary market liquidity (even better than Treasury bonds in some dimension). In addition, from the perspective of most institutional investors, CDB bonds are with same tax-treatment with other fixed-income securities. As a result, CDB bonds are widely accepted as the risk-free benchmark in practice (as opposed to Treasury bonds).

\section{Other Government Bonds}

Other government bonds include central bank bills and other bonds with government support. They are negligible in recent years.

\subsubsection{Financial Bonds (金融佂)}

We classify all bonds issued by financial institutions, including commercial banks, insurance companies, and security firms, as "financial bonds." Because the financial industry, which is considered to be a command-high industry for economic growth, still remains largely state-owned and often with implicit government guarantee, financial bonds are considered to be better risk-profile than corporate bonds issued by non-financial firms. This better risk profile is reflected in a higher rating distribution received by 
financial bonds (see Figure 7 in Section 5.2); there is little difference in yield spreads between financial and non-financial bonds once conditional on ratings.

Negotiable Certificates of Deposit (NCDs, 同业存单)

As a money market instrument, a NCD is a certificate of fixed-term deposit issued by depository institutions in the interbank market. Often the time it is also called interbank CDs, or just CDs. As shown in Table 1, there were no NCDs in 2008. But the NCD market grew rapidly since its inception in December 2013, reaching 9.8 trillion RMB at the end of 2018, thanks to its high credit quality (guaranteed by issuing banks), excellent secondary market liquidity, and reasonable premium over risk-free benchmark offered by government bonds). The NCD rates tracks closely with Shanghai Interbank Offered Rate (Shibor, 上 海银行间同业拆放利率), with a premium of 80 bps over CDB bonds in 2018.

The typical issuers of NCDs are relatively smaller joint-stock commercial banks and urban credit unions, while the buyers of NCDs are large state-own banks (e.g., the Big-five) or their Wealth Management Products (WMPs, 理财产品), as large state-owned banks enjoy cheap funding sources either from retail deposits or various central bank facilities. ${ }^{3}$ Besides large state-owned commercial banks, money market funds and mutual funds (broadly defined to include asset management plans funded by wealthmanagement products) are also investing in NCDs for favorable returns.

\section{Other Financial Bonds}

Other than NCDs, investors can also invest in senior and/or subordinate bonds issued by commercial banks (large state-owned banks, joint-stock banks, and urban and rural credit unions), insurance companies,

\footnotetext{
3 The Big-five banks are Bank of China, Construction Bank of China, Commercial and Industrial Bank of China, and Agricultural Bank of China (these banks are often-called the Big-four) and the Bank of Communications. The issuance of NCDs, especially for rural credit unions, was severely curtailed by the recent Macro-Prudential Assessment regulatory tightening starting May 2017.
} 
security firms, and other financial institutions. These financial bonds contribute to a relative small part of Chinese bond market (about 7\% of the market at the end of 2018).

\subsubsection{Corporate Bonds (产业债)}

The category of corporate bonds broadly covers all fixed-income securities issued by non-financial firms in China, including asset-backed securities and other convertible securities.

\section{Enterprise Bonds (企业债)}

Enterprise bonds, which emerged as early as in early 1980’s, are an important financial instrument used by non-financial firms in China as an alternative to bank loans. After the establishment of the interbank market in 1997, the interbank market became the only market where enterprise bonds were issued and traded, as back then enterprise bonds are mainly issued by SOEs who are not publicly listed in stock exchanges. In 2005, the exchange market started to compete for businesses, and issuing entities can choose to sell their bonds in both markets. As a result, about $82 \%$ of enterprise bonds become dual listed since then, and at the end of 2018, about 1/3 (2/3) of enterprise bonds are issued and traded in the exchange (interbank) market. Wang, Wei, and Zhong (2015) and Chen et al (2018) study dual listed enterprise bonds. For historical reasons, the issuance of enterprise bonds have been always regulated by National Development and Reform Commission (NDRC, 国家发展改革委员会), a powerful government agency that is overseeing SOE reform and relatively remote from PBC and CSRC. The outstanding value of enterprise bonds has reached 3 trillion RMB at the end of 2018, and their investors are mainly commercial banks and mutual funds. 
One important component of enterprise bonds is Municipal Corporate Bonds (MCB, 城投债), ${ }^{4}$ which consist of 75\% of enterprise bonds outstanding at the end of 2018. Municipal Corporate Bonds are bonds issued by LGFVs which are state-owned enterprises to support the infrastructure investment, both at the provincial and city level. They are one of the perfect examples of the mixture between planning and market in today's Chinese economy: they are with implicit backing of the corresponding local government (the word Municipal), but in a strict legal sense they are issued by LGFV entities just like other regular corporations (the word Corporate).

\section{Exchange-Traded Corporate Bonds (公司债)}

Exchange-traded corporate bonds stand for corporate bonds that are issued in the exchange market and regulated by the CSRC. When first launched in 2007, exchange-traded corporate bonds could only be issued by publicly listed companies. In 2015, the CSRC expanded the eligible list of issuing entities in a significant way, which allowed all firms registered as "corporations” to issue exchange-traded corporate bonds. Besides, the CSRC also loosened the bond issuance criterion, and gave greenlight to both public issuance as well as private placement. Since then exchange-traded corporate bonds grew rapidly, reaching 6 trillion RMB at the end of 2018.

\section{Medium-Term Notes ( 中期票据)}

Issued in the interbank market, medium-term notes are mainly used by large SOEs as well as prominent private enterprises since 2008. The typical debt maturity at issuance is between three to five years, but

\footnotetext{
${ }^{4}$ These bonds are also called Urban Investment Construction Bond, or Chengtou Bond which is the phonetic translation of its Chinese name, in other existing papers. Bai and Zhou (2018) offer the first comprehensive study on the pricing of MCBs, and Liu, Lyu, and Yu (2017) investigate the role of implicit local government guarantees for these bonds.
} 
also can go as high as ten years. At the end of 2018, the outstanding bond value of medium-term notes reached 5.7 trillion RMB.

\section{Commercial Papers (including Super Commercial Paper, 短融及超短融)}

Issued in the interbank market, commercial papers are short-term (generally below one year) financing instruments mainly used by large SOEs as well as prominent private enterprises. For commercial paper, the typical debt maturity at issuance is within 1 year, while for super commercial papers it is about 270 days. Commercial papers were launched in 2005, and at the end of 2018, the outstanding bond value reached 1.9 trillion RMB.

\section{Asset-Backed Securities (ABS, 资产支持证券)}

First launched in 2005 and growing by about $49 \%$ per year since then, ABS can be issued and traded in both interbank and exchange markets. As a nascent financial product, ABS is the financing engine behind the peer-to-peer lending platforms, a burgeoning sector that has been experiencing an astonishing growth recently (for example, the micro-financing arm under Ant Financial Services Group). It is also common for commercial banks to issue ABS backed up by consumer or industrial loans, which essentially removes their on-balance-sheet assets to off-balance-sheet. In 2018, the outstanding value of asset-backed securities reached 2.6 trillion RMB, which was about $13 \%$ of the corporate bonds and $3 \%$ of all bonds. Private Placement Notes (PPN, 定向工具)

Launched in 2011, PPN represents one of the financial innovations by the interbank market and essentially is a mixture between private debt and public bonds. Non-financial firms can issue PPNs to a relatively small number of select institutional investors, who then may transfer these notes among themselves before their maturity in the interbank market. Relative to other more standard publicly placed bonds, PPNs face much less stringent requirement of information disclosure, as the issuers can even negotiate the particular way of information disclosure with the small number of select investors. This significantly alleviates the 
concern of information leakage for those small-medium enterprises, especially for those start-ups in the technology sector. After several years of rapid growth, the outstanding PPN has reached 2 trillion RMB at the end of 2018 , which is about $2.3 \%$ of the market.

\section{Other Corporate Bonds}

Other bond products include International Institution Bonds (国际机构债) and Railway Bonds. They are about only $0.5 \%$ of the outstanding bond value in 2018 .

\subsection{Bond Market Liquidity}

The last two columns in Table 2 gives the annual secondary market trading volume and the turnover (trading volume over the average outstanding balance) of each bond during the year of 2018. Among all the categories, financial bonds have the highest turnover of about 4; government bonds rank the second with a turnover of 1.6, and corporate bonds with the lowest turnover (about 0.9).

Chinese government bonds are far less liquid compared to U.S. Treasuries; the latter is perhaps the most liquid financial instrument in the world, with an annual turnover of about 10 in 2018 . The lack of market liquidity for Chinese government bonds is often blamed for its poor functioning in efficient price discovery, potentially hurting the effective monetary policy conducted by the PBC.

Chinese corporate bonds are significantly less liquid than Chinese stocks, with an annual turnover of about 2.3 in $2018 .{ }^{5}$ For a comprehensive study on the liquidity of Chinese corporate bonds and its evolution in response to Beijing's relentless interventions in the last decade, see Mo and Subrahmanyam (2019). That lack of market liquidity of corporate bonds is a universal phenomenon that holds in other developed financial markets like in U.S. and Europe, perhaps because natural corporate bond investors say insurance companies typically keep their holdings until maturity. By calculating the widely used liquidity measures

\footnotetext{
${ }^{5}$ Chinese stock markets have a higher turnover rate than U.S. stock markets, as the investor base in Chinese stock market is mostly retail-driven instead of institutional investors.
} 
between the two bond markets in China and that in U.S. based on, Table 3 shows an overall similarity of the corporate bond market liquidity across these two economies.

Given the unique two-market system in Chinse bond markets, it is interesting to compare the market liquidity between the interbank and exchange markets. Figure 5, taken from Chen et al (2018), plots the number of trades and RMB volumes of corporate bonds in these two markets, respectively. Compared to the interbank market, there are way more trading activities in terms of number of trades in the exchange market (90\% in terms of number of trades, shown in Panel A), but the volume weighted by trading size is miniscule (5\% in terms of RMB volumes, shown in Panel B). This is consistent with Table 3, and reflects the fact that retail investors speculate in the exchange market heavily, while in the interbank market sophisticated financial institutions only trade whenever they need to. In summary, the interbank market is deeper but lacks immediacy, relative to the exchange market.

\subsection{Summary}

Table 4 summarizes the comparison between the interbank and exchange markets, with a detailed list of various bond products traded there. Though largely segmented, these two markets overlap in several key bond products, mainly government bonds and enterprise bonds. Starting 2015, the exchange market opened its access to enterprise bonds, which had been issued and traded only in the interbank market before. Chen et al (2018) provides an analysis on the market segmentation of dual-listed enterprise bonds, whose cross-market arbitrage is severely hindered by the transfer-of-depository which is a timeconsuming process. ${ }^{6}$

\footnotetext{
${ }^{6}$ Suppose investors would like to sell their interbank holdings to the exchange market, perhaps for a better exchange price. According to Chen et al (2018), investors need to apply for transfer of depository from the interbank market (the CCDC) to the exchange (the CSDC), which takes about three to four working days in 2014. The other way around from exchange to interbank will take a slightly longer process (about four to six working days in 2014). The transfer of depository becomes quicker in recent years, but still takes about a few days.
} 
The market segmentation is also reflected in the distinct regulators for these two bond markets. The government agency who is overseeing the exchange market is CSRC, the powerful watchdog for Chinese stock market. In contrast, the interbank market is overseen by the central bank PBC, who is the de-facto gate-keeper of this market. Under the guidance of PBC, National Association of Financial Market Institutional Investors (NAFMII, 银行间交易者协会) is a self-regulatory organization established in October 2007 to formulate rules governing institutional participants in the interbank market. Regulatory competition among different government agencies is a recurrent theme commonly seen during the development of Chinese financial system. For reference, Table 5 provides a complete list of regulators specialized to each detailed bond product. One notable regulator besides the above-mentioned two is the NDRC. As mentioned, the NDRC is in charge of the issuance of enterprise bonds; recently, it has been playing an increasing role in regulating and approving local government debts, including the municipal bonds (issued by local governments directly) and municipal corporate bonds (issued by LGFVs).

The coexistence of OTC-based interbank market and exchange-based bond market is an important feature that is unique to Chinese bond markets. For historical reasons, these two markets have been developed in a relatively independent fashion. Despite the recent effort made by the NDRC to integrate these two markets which gives rise to the dual-listed enterprise bonds (Chen et. al, 2018), we expect the coexistence of these two bond markets to last for quite a long time in China.

\section{A Brief History of Chinese Bond Markets}

This section offers a brief account on how the bond market in China has been evolved to what it looks like now. The thread that connects all the milestone events in Chinese bond market is the segmented market system described in Section 2.1: the exchange market and the interbank market. 


\subsection{Physical Bond Counter Market}

The development of Chinese bond markets in the modern era started from the resumption of the Treasury bond issuance by Ministry of Finance in $1981 .^{7}$ Besides the government, a few enterprises as well as financial institutions were also conducting debt financing from either their own employees or outside investors. These non-bank-loan debt instruments became legal "enterprise bonds" after the release of "Regulatory Guidelines of Enterprise Bonds” by the State Council in 1987. The secondary market for bond trading followed, and in 1988, Ministry of Finance carried out a pilot project for Treasury bond circulation and transfer in 61 cities. Through this program, individual investors can buy and sell Treasury bonds at the bank counters as well as regional trading centers. Trading was done mostly in the form of physical bonds, hence it was called a "physical bond counter market" (Sun, 2015).

\subsection{The Exchange Market Era}

Many deficiencies emerged during the early 1990’s for this physical bond counter market. Among them, the most critical one is the lack of uniform bond custody system. Fake Treasury bonds were common, as it was extremely difficult for decentralized custody systems to verify the authenticity of the physical paper bonds.

The centralized exchange market, with electronic "book-entry" Treasury bonds, was considered to the solution to this problem. Established in December 1991, the Shanghai Stock Exchange provided uniform bond custody service across the country, and the government was explicit in supporting the development

\footnotetext{
${ }^{7}$ Without market-based mechanism at play, allocations of Treasuries were based on apportionment via administrative channels at that time.
} 
of this exchange bond market. ${ }^{8}$ In August 1995, the government officially announced that stock exchanges, including both Shanghai and Shenzhen Stock Exchanges, were the only legitimate bond market in China. This greatly improved the liquidity and functioning of the secondary market on these two exchanges, and an exchange-based bond market system has shaped by 1996.

It was not long before another dramatic turn that pushed the interbank market onto the stage. Keep in mind that the two exchanges in China are developed mainly for equity financing and stock trading. During the first half of 1997, the Chinese stock market experienced an unprecedented boom, witnessing Shanghai Ashare index rising from 1000 in early 1997 to above 1500 in May 1997. The secondary bond market activities, which involve commercial banks and individual investors, contributed to this speculation-driven stock market surge. Essentially, bond repo transactions in the exchange market allowed investors to use bonds as collaterals to obtain debt financing from banks, which in turn was channeled toward the stock market to fuel its rally.

\subsection{The Rise of Interbank Market}

Worrying about the large amount of bank funds that flowed into the overheated stock market, on June 1997 the PBC ordered all commercial banks to withdraw from exchanges and switch to the newly established interbank market. The PBC also mandated that all commercial banks move their Treasury bonds, central bank bills, and financial bonds issued by policy banks into the interbank market under the custody of CCDC.

\footnotetext{
${ }^{8}$ These initiatives include the pilot program of convertible bonds and the short-lived episode of Treasury futures trading on the exchange. Shanghai Stock Exchange introduced the Treasury future contracts in December 1992, but terminated them in May 1995 after the infamous scandal of “The event of 327 Treasury Future Contract.” The Treasury future market in the exchange was resumed in September 2013.
} 
This PBC-led event marked the beginning of the dramatic growth of interbank bond market. During the next twenty years, the "wholesale" interbank market, standing in contrast to the more-or-less "retail" exchange market, has become the dominating pillar of Chinese bond markets. The participants were initially restricted to only 16 head offices of commercial banks in 1997; by the end of 2000, a total of 693 financial institutions, including insurance companies, urban and rural credit cooperatives, and security firms, had become members of the interbank market.

In February 2014, facing the rapid rise of “shadow banking business," the PBC allowed 16 large commercial banks to invest their own WMPs in the interbank market. In May 2016, direct accesses to the interbank market were further granted to all qualified institutional investors, including WMPs, investment funds and trust companies. The total number of the interbank market members has reached 6,543 in December 2018, and these financial institutions are covering almost the entire financial system in China nowadays.

\subsection{Bond Markets and the Growth of Chinese Economy}

The rapid and steady development of the Chinese bond market offers great benefit for various economic agents in Chinese economy. First, the interbank market has become the primary place for the Ministry of Finance and government-backed entities like policy banks to issue bonds to finance their activities. Second, it helps the central bank, the PBC, to implement its open market operations and other monetary policies. For instance, in April 2003 the PBC conducted the first formal open market operation in the interbank market, by issuing central bank bills valued at 5 billion RMB with a maturity of 6 month. We are coming back to this topic in Section 4.1.

But perhaps an equally important role played by the Chinese bond market is to channel household savings toward the real sector, which is critical for the Chinese economy to achieve its astonishing growth in the last three decades. Various forms of debt instruments have been developed in both markets. In the 
interbank market, commercial papers, a form of short-term high-quality enterprise bonds with a typical maturity of below one year, emerged in May 2005; and medium-term notes with a typical maturity of five years saw their debut in April 2008. On instruments besides enterprise bonds, the first Asset Backed Securities were issued in the interbank market in December 2005; and the first Municipal bonds (by local governments via Ministry of Finance) in April 2009. On the exchange market, listed companies first issued exchange-traded corporate bonds in 2007, and in 2015 the CSRC expanded the eligible list of corporate bond issuers to all incorporated companies (as opposed to only listed companies). All these reform activities gave a great boost for the development of corporate bonds market in China.

\section{Issues and Recent Trends of Chinese Bond Markets}

In this section, we first point out that a full market mechanism is yet to be achieved by Chinese bond markets. We then highlight the predominance of commercial banks in China's bond markets; this also explains why the Chinese bond markets are deeply intertwined with the shadow banking system in China. We finally discuss the recent trend since late 2017 in authorities' hardline stance in deleveraging and restraining shadow banking activities, together with opening up Chinese onshore bond markets to international investors.

\subsection{Interest Rate Determination and Monetary Policy Transmission}

The risk-free benchmark interest rates and the associated term structure, which are implied by the prices of all government bonds with various maturities, "anchor" the pricing of all financial assets in modern financial markets. Like in other modern financial markets such as U.S., interest rates of newly issued Chinese government bonds are determined via competitive bidding of participating financial institutions (mainly commercial banks and securities firms) in the primary market; they then can trade among each 
other in the secondary market. Today, it is fair to say that market mechanisms are at work in Chinese bond markets after more than two decades of successful and continuous development.

Figure 6 plots the yields for Treasury bonds and CDB bonds for 1 and 10 year maturities, respectively. These four series of interest rates are moving mostly in parallel and varying between $1.5 \%$ and $6 \%$ since 2012, with slightly lower yields for Treasury bonds (than CDB bonds) due to their tax advantage. Overall, in the past half decade, the term structure of interest rates in China is upward-sloping, and the steadily falling interest rates over the period of 2013-2016 made this episode the "bull” market for Chinese bond traders.

Despite the rapid growth in the size of the bond market, it is well-recognized among policy makers and practitioners that Chinese bond markets are still underdeveloped in many key dimensions. Compared to the deep and liquid market for U.S. Treasuries, the market for Chinese government bonds still lacks sufficient liquidity, and is often blamed for its poor functioning in efficient price discovery. The latter role of price discovery is key to the effective monetary policy conducted by the PBC in stabilizing the Chinese economy.

There are several institutional reasons for the steady but somewhat slow development of the Chinese government bonds market toward a full market mechanism. A well-functioning primary and secondary market for risk-free rate determination is an integral part of interest rate liberalization, which started in the late 1980s and saw its formal completion when the PBC finally lifted the banks' deposit rate cap and rolled out the deposit insurance scheme in 2015. Second, the " $12^{\text {th }}$ five-year plan" in 2011 has made it clear that future monetary policies should put more emphasis on market-driven price-targeted tools (e.g., repos with the PBC, and Standing Lending Facilities), although quantity-targeted tools (e.g., M2 growth or total bank credit) and "guidance rates" frequently published by the PBC remain until today the most effective measures taken by Chinese monetary authorities. Third, from a market design perspective, an entry barrier 
exists for the primary market, which limits participation in the auctioning of government bonds to qualified financial institutions. Most of market-makers, who serve the secondary market in the interbank market, are commercial banks with unpleasantly high degree of homogeneity in trading strategies and funding sources. Finally, the above-mentioned segmentation between the interbank and exchange markets, with potential violation of the "law of one price," hurts price discovery and liquidity of Chinese government bond market.

\subsection{The Role of Banks and Shadow Banking}

Another distinct feature that seems to be inconsistent with the fast development of Chinese bond market is that the participants remain highly concentrated in one particular type of financial institutions: commercial banks. As explained in Section 3.3, the Chinese interbank bond market has been closely intertwined with the banking system ever since the establishment of the bond market in 1997, when commercial banks were mandated by the PBC to be the first participants of bond issuance and trading. It is crucial to recognize that the official statistics significantly underestimates the dominance of commercial banks in Chinese bond market. It is well-known among practitioners and regulators that in China, commercial banks participate in the bond market via two channels: the direct on-balance-sheet channel, through which the bank's so-called financial market division buys and sells bonds (and engage in even arbitrage trades) in the interbank market; and the indirect off-balance-sheet channel, where the bank's asset management division sets up some wealth management plans (just like Special Purpose Vehicle in the U.S. market) financed by WMPs and invest in both interbank and exchange markets. The dominating share of commercial banks (57\%) of the interbank bond market in Figure 2 only counts the first channel.

This perspective suggests that in China's financial system, corporate bonds, to a significant extent, can be considered another form of disguised bank financing. Facilitated by the growingly sophisticated shadow- 
banking activities, the transfer of on-balance-sheet loans (inside the traditional banking system) to offbalance-sheet assets outside (say corporate bonds) is commonly observed, especially when banks were facing tightened regulation on the overheated real estate sector and LGFV financing. This is why practitioners often argue that, different from other developed countries, in China the shadow banking is literally just the "shadow" of commercial banks.

Let us take the example of WMPs, which are the biggest component of shadow banking in China and the most important vehicle to connect back to the banking system. Starting 2014, China Banking Wealth Management Registration System releases its annual report on WMPs, which gives an official account on the role played by WMPs in today's Chinese financial system. According to these reports, a majority of WMP is invested in the bond market, with the percentage to be $44 \%$ in 2016 and $42 \%$ in 2017 .

In fact, many industry reports corroborate this view. Ehlers et al (2018) estimate that $38 \%$ of the net issuance of all bonds is funded via bank-issued WMPs in 2014; the funding percentages are 35\% and 31\% in 2015 and 2016, respectively. In a more recent study, Lei et al (2018) find that 7 trillion out of 18 trillion outstanding corporate bonds' balance is funded by WMPs; and as explained in footnote 8 , these numbers are likely to be biased downward. Overall, evidence suggests that bond market is an integrated part of the bank-dominated shadow banking in China.

Chen, He, Liu (2018) argue that the China's the shadow banking problem is connected to the local government debt problem, which is further rooted in the four-trillion stimulus rolled out in 2009. They document that three to five years after the 2009 stimulus plan, LGFVs need to refinance their maturing bank loans and/or fund the ongoing infrastructure projects. However, soon after mid-2010, indebted LGFVs were squeezed by tightening credit standards from traditional banks. As a result, these LGFVs then started issuing Municipal Corporate Bonds (MCBs, as explained in Section 3.3) in the interbank 
market. The majority of these MCBs was bought by WMPs, which was sold and implicitly guaranteed by commercial banks. $^{9}$

There is another important channel through which commercial banks facilitate industrial firms to issue bonds in the interbank market and hence are exposed to default risk. In China, commercial banks often engage in guarantee provisions on corporate bonds, though it is hard to estimate the severity of this risk exposure.

To illustrate this point, consider the interesting case on the scandal of Cosun bonds (侨兴债事件), which involves financial innovations, shadow banking, and (some malfunctioning of) the commercial banking system. In December 2016, the Cosun Group, a privately-owned Telecommunication company in Guangdong, defaulted on a series of its privately placement notes issued two years ago. ${ }^{10}$ Shocked by the default news, retail investors went to Zheshang Insurance, the insurance company which provided insurance on this credit event. But Zheshang Insurance immediately made a public announcement stating

${ }^{9}$ Chen, He, Liu (2018) find that about $60 \%$ of MCBs are invested by WMPs by the end of 2016 . This $60 \%$ number is likely to represent an underestimation of the extent to which MCBs are relying on WMPs with the ultimate endorsement of banks. Before the 2017 regulation tightening on China's shadow banking activities, it was popular for managers of WMPs to invest in asset management plans (or several layers of asset management plans, like CDO square in the U.S. market before the 2007/08 financial crisis), which then eventually invest in MCBs. The official statistics ignores this indirect exposure of WMPs in MCB (hence introducing a downward bias of our estimate). According to practitioners in this market, the rough estimate of the true exposure is that about 70\% of MCBs were invested by WMPs around 2016.

${ }^{10}$ These notes were placed in a local-government owned (Guangdong) exchange market) but sold through some peer-to-peer platform to retail investors, with the help of financial innovation. Recall that PPNs are only allowed to be invested by a select group of sophisticated institutional investors. However, it turns out that many retail investors are buying pieces of PPNs issued by Cosun Group, thanks to the financial innovation by some peer-to-peer lending platform. 
that China Guangfa Bank, one of the earliest-incorporated joint-stock commercial banks, had promised some guarantee provision to repay Zheshang Insurance at the bond issuance but reneged on its promise. It turned out the Huizhou Branch of China Guangfa Bank provided a “counterfeit” letter of guarantee for this bond issuance; ${ }^{11}$ this guarantee helped Cosun to issue these bonds, only to rollover Cosun’s maturing loans extended by the Huizhou Branch itself several years ago.

\subsection{Regulatory Tightening Starting 2017}

The Chinese government is well aware of these "shadow of bank" activities that essentially tie the commercial banking sector to the financial products offered in the interbank market. The dramatic regulatory change started in 2017 is expected to reshape the Chinese financial market in a profound way, bringing a sea change in the interbank market. Under this new framework, WMPs will be put under the scrutiny of the PBC for the first time and into its calculations on prudence, capital adequacy and loan growth guidelines. Another equally important regulatory tightening is on the rules of new asset management plans, first proposed in Nov 2017 and released in April 2018 (though still yet to be finalized). The new rules aim to prohibit implicit guarantee and multi-layer structure, the two important ingredients that had contributed to excessively high leverage in China's shadow banking system in the past decade. Not surprisingly, in response to policy tightening, the Chinese bond market experienced a dramatic downward adjustment in 2017. The annual increment of the value of outstanding bonds, adding together the interbank and exchange markets, experienced about a 35\% of drop going down from 16 trillion RMB

\footnotetext{
${ }^{11}$ After the credit event, Zheshang Insurance released documents carrying Guangfa Bank’s official seals, showing that the bank’s Huizhou branch had promised the guarantee. However, the headquarter of Guangfa Bank claimed that the guarantee documents presented by Zheshang Insurance, together with official seals and personal seals, were “all fake.” For details, see https://www.reuters.com/article/uk-china-banksfraud/china-imposes-record-fine-on-guangfa-bank-over-guarantees-for-defaulted-bonds-idUKKBN1E21KU.
} 
in 2016 to 10 trillion RMB in 2017 and 2018. We will come back to this topic in Section 6.2 together with the recent insurgence of corporate default in Chinese bond market.

Looking forward, we believe that Beijing's recent effort in streamlining and tightening regulations in the ever-complicated Chinese financial market is well justified. Though it is inevitable to bring pain to market participants in the short-run, a transparent regulatory environment is tremendously important to build a healthy and sophisticated bond market in a modern financial system where market participants understand fully the consequences of their own decisions, including issuance, underwriting, trading, and investment.

\subsection{Internalization of Chinese Bond Market}

Despite the fact that the Chinese bond market has developed to be third largest in the world, the foreign participation is miniscule. At the end of 2018, the total foreign holdings of the Chinese bonds reached 2.6 trillion RMB, or around 3.1\% of the bond market capitalization. ${ }^{12}$

Historically, to gain access to Chinese bond market, offshore investors were required to go through some quota-based foreign investment programs. One of them is the Qualified Foreign Institutional Investor (QFII，合格境外机构投资者) program, which was launched in 2002 and regulated by State Administration of Foreign Exchange (SAFE, 国家外汇管理局, a powerful arm of PBC) which monitors the remittance and repatriation of funds across the border. Initially QFIIs could only invest in the exchange bond market; since March 2013 they are allowed to get access to the much bigger interbank market. Another closed related program is the Renminbi Qualified Foreign Institutional Investor (RQFII, 人民币 合格境外机构投资者) program. This program allows domestic financial institutions to establish RMB

\footnotetext{
${ }^{12}$ On the other way around, many Chinese firms have actively sought oversea funding sources by issuing foreign-currency denominated bonds (Huang, Panizza, and Portes, 2018).
} 
denominated funds in Hong Kong, attracting offshore RMB in the hands of oversea investors back to the onshore bond market. At the end of 2018Q3, the total quota combining QFII and RQFII was about 1.34 trillion RMB, though the actual usage was just 0.3 trillion RMB (within which about $10 \%$ was invested in bonds while the rest was in equities). ${ }^{13}$

As a milestone effort in the effort of internalization of RMB, Beijing launched the PBC bond direct-access program in 2010. Based on a case-by-case approval system, this program attracted offshore institutional investors (e.g., foreign central banks and offshore RMB clearing banks) to the Chinese interbank bond market. In July 2015, the PBC further eased the regulation by allowing institutions with long-term investment mandates--such as foreign central banks and sovereign wealth funds--to participate in the interbank market without quota limits. More importantly, these qualified institutions can follow a registration system, rather than a pre-approval system, to participate in the interbank market. In February 2016, similar accesses were granted to a much wider range of institutional investors, including commercial lenders, insurance companies, securities firms and asset managers (excluding short-term or “speculative” investors). One year later in February 2017, the SAFE was giving overseas investors access to its foreignexchange derivatives market to allow hedging of bond positions, a crucial step in attracting foreign inflows. On an almost independent effort, motivated by the success of Stock Connect started in November 2014, China launched its Bond Connect (债券通) on July 2017. Like Stock Connect, Bond Connect is a mutual market access scheme that allows investors from mainland China and overseas to trade in each other's bond markets, through connection between the related mainland and Hong Kong financial infrastructure institutions. Thanks to Hong Kong being the leading world-class financial center, foreign investors offer

\footnotetext{
${ }^{13}$ Unfortunately, we only have data for stock investments in QFII. We hence estimate the total investment of QFII and RQFII using 90\% invested in stock and 10\% in bond and assuming the same investment structure for RQFII.
} 
a warm welcome to Bond Connect: The rise of foreign ownership of mainland bonds in July and August in 2017 almost doubled the pace of the prior year.

No doubt, the sophistication and development of mainland bond markets are crucial for advancing RMB internalization, one of the policy goals that has received top priority for Chinese government. Looking forward, given Beijing's strong intention to push forward the liberalization of the mainland bond market, we expect a more and more relaxed regulatory environment for foreign investors to participate. Like-wise, oversea investors are flocking to China's mainland bond market for its strong value and potentially tremendous opportunity. This process is likely to be expedited by the decision of Bloomberg, which announced that, starting April 2019, it will add over 300 China’s government bonds into the Bloomberg Barclay’s Global Aggregate Bond index. Of course, this progress might be interrupted by the concerns of capital flight in the wake of potential significant slowdown of Chinese economy.

\section{Bond Ratings and Rating Agencies}

A key characteristic of bonds is their credit risk as reflected in ratings. Rating agencies are vital in any financial market. While rating symbols used in China closely follow global standards, the rating scale differs. China has currently de-facto only three rating categories. This section illustrates and discusses the skewed rating distribution. Reasons for this observation include low default rates, ongoing trend of more upgrades than downgrades, implicit guarantees, regulatory requirements and a fierce competition among the domestic rating agencies, which differ little in their ratings assessments. The previous section introduced three different bond types. As ratings for government bonds are always AAA rated, this section focuses on “credit bonds” including financial and corporate bonds. ${ }^{14}$

\footnotetext{
14 “Non-financial credit bonds" and "corporate bonds" are used as synonyms in this section.
} 


\subsection{China's Credit Rating Scale}

China's domestic rating scale includes nine long term grades (AAA, AA, A, BBB, BB, B, CCC, CC, C) and six short term grades (A-1, A-2, A-3, B, C, D) as officially set by the PBC. This is in line with international standards as set by the globally dominating three U.S. based rating agencies Moody's, Standard \& Poor's and Fitch. However, there are two main differences in the rating scale used by Chinese versus global rating agencies. First, the definition of investment grade differs. In China AA is generally seen as the lowest investment-grade level while this is BBB in global ratings. Despite the higher threshold, the issuance of non-investment grade bonds is much scarcer in China. Second, China's domestic rating scale knows an additional, informal rating grade: the AAA+" or "super AAA" category provided by investors. These AAA+ issuers keep an official and legally relevant rating of AAA provided by rating agencies. However, the AAA+ issuers enjoy a higher weighting in valuation indices, reflecting lower default probability assigned by investors who expect these corporates to essentially have a credit risk similar to government bonds. By 2018, there are 10 central-government owned issuers in this category (Table 6).

\subsection{Distribution of Credit Ratings}

The distribution of the Chinese ratings is well-known to be skewed to the upside (Kennedy 2008, Poon 2007, Standard Chartered 2017). Despite the large market size (about 2,000 corporate issuers) on global standards, over $95 \%$ of the outstanding amount of non-financial credit bonds are covered in only three rating categories (Figure 7 Panel A). By the end of 2018, 54\% of the corporate bond outstanding in China enjoys an AAA rating, versus about $6 \%$ in the U.S. corporate bond market. $23 \%$ is AA+, another $19 \%$ is AA rated and only $2 \%$ are rated as AA- and below and therefore as non-investment grade. $1 \%$ of the outstanding amount of corporate bonds are not rated. For financial bonds, the shares are AAA 82\%, AA+ $13 \%$, AA $4 \%$ and AA- or lower $1 \%$ of the outstanding amount of corporate bonds respectively, reflecting 
the explicit government guarantees. The high share of AAA rated corporate bonds in value terms is partly explained by large amounts of bond issuance of just a few issuers who are mostly linked to government. Of the top 10 issuers (Table 7), only one is privately owned, which is a real estate corporate, while the others are all central SOEs. However, clustering in only three categories also holds in terms of the number of issuers. Of the Chinese corporate issuers, $14 \%$ hold an AAA rating, $19 \%$ an AA+ rating and $41 \%$ an AA. About $8 \%$ of corporate bonds are private placement, where credit ratings are not mandatory. Only 18\% hold a non-investment grade rating of AA- and below (Figure 7 Panel B). Consequently, China currently has essentially no high yield or speculative grade bond market.

The tilted distribution is controversially discussed. On one hand, the low credit risk differentiation is generally seen as a hindrance to the development of the bond market. For domestic investors, the absence of a more granular credit risk opportunities and the lack of a speculative, high yield market might lower the attractiveness of the bond market particularly relative to the stock market. For international investors, the low guidance offered by the current rating distribution is often given as one reason why they currently take up only a small part of the investor base in the Chinese bond market, despite a steady loosening of investment restrictions (Section 4.4). On the other hand, implicit guarantees entailed in the credit assessments of a good part of corporate issuers with links to government may partly justify a higher rating. ${ }^{15}$

\subsection{Low Default Rate, Implicit Guarantees and Rating Migration}

Low default rate

\footnotetext{
15 This is similar to the case of “stand alone” versus “support” ratings assigned to some international banks, which enjoy a lower default risk and higher all-in rating due to government support schemes.
} 
A main reason for the high credit ratings is the very short and limited history of defaults in China. The first onshore public bond default occurred only in 2014. The defaulted amount in the Chinese bond market amounted to only 1.26 billion RMB in 2014, reached a first peak at 30.1 billion RMB in 2016, before falling to 27.7 billion RMB in 2017. The amount of defaults jumped to a new high of 128 billion RMB in 2018 (Figure 8 Panel A in Section 6.1). This surge in corporate defaults was triggered by challenging refinancing conditions and increasing redemptions (mentioned in Section 4.3) due to tightened regulation starting end of 2017. However, since the first default in 2014 until the end of 2018, the defaults represented only $0.2 \%$ of the overall outstanding amount, suggesting a rather small default probability relative to the global counterpart. See more details on corporate bond defaults in Section 6.

\section{Rating migration}

As the number and amount of defaults start to increase, though at quite low levels, one would expect that this trend slowly but steadily softens the skewness of the rating distribution. However, the opposite was so far the case. Since the first default in 2014 until 2018, there were about ten times more upgrades than downgrades (Table 8). Of the 2,784 bond issuers 918 received rating upgrades, only 129 were downgraded and the vast majority of 1737 remained the same rating level over the past four years until end of 2018. The biggest rating migration occurred for the AA- rated bonds where over $49 \%$ were upgraded and only $6 \%$ downgraded. Of the large share of AAA rated bonds only $2 \%$ were downgraded. The mismatch between increased defaults and ongoing trend of an upward bias in rating changes lets many commentators

doubt whether the upgrades are backed by improvement in credit fundamentals. Alternatively, they suggest that this phenomenon is related to the fierce competition among the many Chinese rating agencies which we cover in Section 5.5 .

Rating migrations are also discussed in the context of their timing, which is sometimes seen as too late or too hesitant, despite signs of weakening cash flow and earnings. As illustrated by the examples given in 
Section 6, rating changes in cases of bonds that later eventually default occur often alongside announcements and media reports of financial distress. This somewhat limits the use of ratings as an early warning system for investors.

\section{Implicit guarantees}

The low default rate and rating migration is often related to implicit guarantees. While it is difficult to quantify the amount of defaults that are prevented by government support, in some cases ratings are obviously adjusted due to expected, even though not legally binding, moral commitment of the Chinese government. As an example we refer to the bonds issued by the four asset management companies (AMCs, 资产管理公司) that were established to purchase overall 2.4 trillion RMB non-performing loans from commercial banks during early 2000’s. The rating agencies considered the AMC bonds not as speculative but as part of the highly rated Chinese sovereign debt, expecting the Ministry of Finance to step in in case of default. Although implicit guarantees are not a unique Chinese feature as the case of Fannie Mae and Freddie Mac in the U.S. illustrates, the degree of implicit guarantees is likely more severe in China due to more widespread or closer links of corporates to the government.

\subsection{Regulatory Framework}

The regulatory framework is another important factor that supports the clustering in only the three highest rating classes.

\section{Rating requirements}

For corporate bonds to be qualified for public issuance, minimum ratings are mandatory, but in most cases only one rating is required. This makes it often the main motivation for issuers to buy a rating and invites rating-shopping. The specific regulatory requirements vary with the bond type and are set by the respective regulator. For instance, in the interbank market, NAFMII asks for commercial papers and medium-term 
notes issuers to be rated AA- or above. ${ }^{16}$ For exchange-traded corporate bonds that are issued to retail and qualified investors, they generally need an AAA rating, except for issuers in the property sector where a rating of AA or above is sufficient. However, the CSRC removed the rating requirements for corporate bonds that are issued only to qualified investors. Also, the NDRC has its own rating requirement for enterprise bonds. Guarantees are only required for LGFVs with debt-to assets ratios of $65 \%$ or above. No guarantee is needed in the case of an AAA rated issuer of an enterprise bond with ratios below $85 \%$ and AA+ rated enterprise bond issuer with ratios below $80 \%$.

\section{Repo eligibility and haircuts}

The possibility to use a bond as collateral in a repo transaction, which is essentially a collateralized borrowing, is an additional value to bondholders. The greater the haircuts are, the lower the ability of collateralized borrowing is. Bond issuers may therefore be hesitant to issue bonds which lack this property. The repo eligibility of corporate bonds is limited as they are generally only accepted by non-bank financial institutions while banks accept only government bonds. Further, money market funds as key players in the liquidity provision are allowed to accept only bonds rated AA+ or higher as repo collateral.

The repo eligibility on the exchange market is even more restricted, due to its centralized nature. In this market, investors conduct repo transactions against the CSDC who serves as the Centralized CounterParty (CCP, 中央对手方) and sets bond-specific haircuts. Chen et al (2018) document that haircuts are almost entirely determined by bond ratings, and explore the Dec 2014 policy shock when the CSDC suspended the repo eligibility for enterprise bonds with ratings below AAA. Later in 2017, the CSDC tightened the required minimum rating from AA to AAA for exchange-traded corporate bonds.

\footnotetext{
${ }^{16}$ For super commercial papers, two ratings from different agencies are mandatory with one at AA or above.
} 
Overall, the regulatory framework offers clear incentives to issue ratings only in the very high rated categories. It seems unlikely for bond issuances to receive a broader range of credit categories without at least some further loosening of the regulatory restrictions in that respect.

\subsection{Rating Agencies}

The specific structure of rating agency industry in China is a further reason for the upward-skewed ratings in China. After a brief historical review, we discuss the increasing diversification by nationality, the incentive model of rating agencies and possible impacts on the rating distribution.

\section{A brief historical review and licensing}

An early form of rating agencies were already established in 1987 when the State Council issued the “Regulatory Guidelines of Enterprise Bonds”, which introduced ratings in their guidance of bond issuance. At first ratings were offered by credit rating departments in provincial branches of the PBC. Later a series of independent rating agencies took up business, in some cases as a spin-off of the previous rating departments. The PBC regulations on the types of bonds and loans requiring a rating became mandatory from 1993 onward, further fueling the offering of rating services. To assure quality and consistency in the rating agency industry, the PBC demanded since 1997 that corporate bonds must have at least one rating from a PBC-approved agency and limited the number of qualified rating agencies to nine. In 2006 the CSRC followed with a formalized licensing process for credit rating agencies covering bonds regulated by the CSRC. Today, each of the three regulators covering corporate bonds (NAFMII, NDRC, CSRC) issues separate lists of qualified agencies for rating bonds under their respective program. Consequently, a rating agency usually needs to get approval by more than one regulator depending on which types of 
bonds they are providing rating services for (Table 9). ${ }^{17}$ Recognizing the fragmented accreditation process for rating agencies, the State Council started in 2014 to issue notes that deregulate at least partially and to simplify the accreditation of domestic agencies.

\section{Nine approved rating agencies}

The international rating agency industry is famously dominated by three U.S.-based agencies Moody's, Standard \&Poor's and Fitch. About 95\% of all globally outstanding ratings are currently provided by these so-called Big3. ${ }^{18}$ China has a relatively large number with nine recognized domestic credit rating agencies (Table 9 provides an overview on market share and accreditation). However, six agencies (or four counting the sub-institutes as one) dominate with a market share of $91 \%$ of the outstanding bond issuance in China: Chengxin (Chengxin Securities Rating and Chengxin International Rating), Lianhe (China United Rating and China Lianhe Rating) and Dagong Global Credit Rating. Both Chengxin and Lianhe have a domestic agency licensed by the CSRC to offer ratings in the exchange market, and a separate joint venture licensed by the PBC with a minority ownership of an international rating agency to offer ratings in the interbank market. The fully domestically owned Chengxin Securities Rating, China United Rating and Dagong were founded in 1992, 2002 and 1994, respectively. Chengxin International Rating was established in 2006 and 49\% of its shares are owned by Moody's while Lianhe Rating was established in 2007 and 49\% of its shares are by Fitch ratings. S\&P has a partnership with Shanghai Brilliance Investor Service since 2008. It is worth emphasizing that all the joint-ventured rating agencies mentioned above are operating

\footnotetext{
${ }^{17}$ Further, China Insurance Regulatory Commission, the regulator of the insurance sector (which was merged with China Banking Regulatory Commission in early 2018), once issued a list of recognized agencies for fixed income investments of domestic insurance companies.

18 The global agencies made earlier attempts to enter the Chinese rating industry but at the time decided to disinvest. Fitch had a joint venture with Chengxin from 1999 to 2003 and Moody’s a cooperative agreement with Dagong from 1999 to 2002 (Lee, 2006; Moody’s, 1999).
} 
completely separately from the corresponding international global rating agency, who takes no active role in the joint ventures.

All this time, the global rating agencies could have only minority stakes in joint-venture operations. Further, they were not accredited to issue "national ratings", ratings of Chinese firms issuing bonds onshore. Instead, the global agencies assign "international ratings" for Chinese firms issuing bonds offshore. In July 2017, the PBC announced liberalization steps on both accounts. Global rating agencies will be allowed to register for rating services in the China interbank bond market and to own a majority stake in an accredited agency, provided that the agency meets some criteria in terms of market experience and corporate governance.

Aside from the five major agencies mentioned above, there are four domestically-owned accredited agencies with a relatively small market share. Shanghai-based Shanghai Brilliance was founded in 1992, Pengyuan Credit Rating based in Shenzhen in 1993, Golden Credit Rating International based in Beijing in 2005 (often labeled as “Orient” in the market), and China Bond Rating Corporation in 2010. China Bond Rating Corporation is the only agency operating under an investor-pays model, a topic that is covered in the next section.

\section{Little differentiation of rating agencies}

While in the early days of rating agencies in China standardized procedure was missing, the rating industry is seen as too homogenous today. Rating methodologies, including the specific factors and weights that are used to determine default probabilities, may only differ slightly. Also, rating decisions across domestic agencies offer little variation and are also similar in timing. None of the domestic agency has gained a clear advantage in reputation or market leadership. Consequently, the rating industry in China is highly competitive with similar fee structures. For agencies, the incentive to pro-actively downgrade an issuer is low. The problem worsens as bond issuers often aim for just one rating in order to fulfill regulatory 
requirements. This is obviously only the case under the issuer pays model, which is the international standard and the model for eight of the nine officially approved Chinese agencies. Recognizing the challenging incentive structure, in 2010 the NAFMII installed an agency China Bond Rating Corporation (CBR, 中债资信) that operates under the investor pays model. On average, CBR offers a stricter rating scale, with two to three notches below the issuer pays model.

There is little difference in rating assignments between the joint ventures and fully domestically owned agencies. It remains to be seen to which extent the recently allowed entrance of foreign rating agencies will change the upside bias in ratings. Comparing ratings from domestic versus global agencies, Jiang and Packer (2017) find the latter to be six to seven notches lower on average. Furthermore, they find differences in underlying drivers. Domestic agencies weigh size more positively in the risk assessment, while global agencies weigh profitability and state-ownership more positively and leverage more negatively. These findings can only serve as an indication since currently the sample of bonds rated by both domestic and global agencies is limited. Moreover, as long as a single domestic rating fulfills the regulatory requirements, the appetite of domestic issuers to buy an additional global rating remains unclear. This status quo might change however, once Chinese issuers see value in broadening their investor base and tapping the large but yet still underutilized pool of foreign investors, particularly institutional investors.

\subsection{Outlook}

The large and increasing Chinese bond market contrasts with the low diversification in credit risk as measured by ratings. We have mentioned a series of contributing factors. Therefore, a change might not be imminent for the ratings provided by the approved agencies we covered here, though shortcoming of the current narrow and upward skewed rating distribution is obvious. Consequently, there is a strong appetite for alternative rating procedures, especially due to the rising interest from oversea investors. A straightforward approach already used by some market participants is to complement the third-party rating 
agencies with market-implied credit ratings, which is determined by comparing the bond's secondary market value against valuation indices. Along these lines, in October 2017, CCDC announced a plan to offer market-based ratings using available information through their oligopolistic custodian and clearing services. We can expect more market-driven initiatives of this kind.

\section{Credit Spreads and Defaults in Chinese Bond Market}

Ever since early 2014, China has witnessed a wave of credit events, which quickly peaked in 2016 mainly driven by the tightened liquidity and deepening financial deleveraging campaign. Despite the relatively tiny amount of defaulted bonds compared with the entire market, the jitters aroused by the default shocks have expanded far beyond the bond market, even to the entire Chinese financial system and the macro economy. Investors' priors of “implicit government guarantee” was gradually broken; financial institutions ceased taking it for granted that corporate bonds are absolutely safe and began to put more and more emphasis on the credit risks underneath the firms.

\subsection{Bond Defaults in China: A Summary}

The unprecedented bond default event of “11 Chaori Bond” on March 5th, 2014 marked the elimination of implicit government guarantee, opening a new era of Chinese bond market. The issuer, "Shanghai Chaori Technologies Inc.” failed to pay its interests in full in the exchange market, constituting the firstever default in Chinse bond markets. We will review several landmark default cases in Chinese bond market in Section 6.3, together with a discussion of recent progress in bankruptcy rulings in China.

Up till December 31, 2018, there have been 263 defaulted bonds, involving 111 issuers in total. Figure 8 Panel B plots the distribution of these default events since 2014, as a fraction of the entire corporate bonds market in China, based on Wind database. A total of 94 private firms have defaulted, taking up a larger percentage of the issuers sunk in defaults. For state-owned firms, there are 11 defaulting SOEs owned by 
local governments, while only 6 are central SOEs. Industry-wise, before 2017, defaults were concentered in those over-capacity "old economy" sectors like coal, steel, and commodity-related industries; but in 2018, the fraction of the "new economy" defaulting firms rises. Finally, the percentage of total amount of defaulted bonds remains quite low, standing at $0.6 \%$ in its peak year of 2018. In contrast, the global counterpart during 2008-2017 is $1.8 \%$ according to a recent report by Moody’s. ${ }^{19}$

\subsection{Defaults, Bond Ratings, and Credit Spreads}

Credit ratings should reflect the bonds' default probabilities. Before 2014, ratings were not that indicative in China, due to the widely perceived "implicit government guarantee" among bond investors. The springup of bond defaults in recent years brings investors' attention back to ratings. Figure 9 plots the credit spreads of enterprise bonds, which is defined as the bond yield minus the matched CDB yield, across all ratings classes since 2013. The credit spreads of lower-rated enterprise bonds ( $\mathrm{A}$ and $\mathrm{BBB}+$ ) experienced a clear upward trend since early 2014, dipped a bit in 2017, but soared again in early 2018.

Typically, both bond-level and issuer-level ratings are downgraded before the default event, following negative public announcements by firms. This partly explains the dispersion of credit spreads across ratings in Figure 9. For example, before the default of "16 Katie Bond" on June 1, 2018, the bond rating status was adjusted to "Negative” on September 1, 2017, and the issuer, Sunshine Katie Co., Ltd., was downgraded by Pengyuan (one of the rating agencies) to "BBB" and put in the "credit risk" watch list on May 8, 2018.

The evolution of the credit spreads and their dispersions in Figure 9 reflect not only the perceived default probabilities across various rating classes, but also the credit conditions of the bond market as a whole.

\footnotetext{
19 This estimation is derived from “Annual Default Study: Corporate Default and Recovery Rates, 1920 - 2017” by Moody’s, which covers the credit histories of more than 25,000 corporate issuers that had long-term rated bonds between 1920 and 2017.
} 
The burst of bond defaults in Chinese bond market, the continuing tightening credit and policy environment in combination with investors' jitters contribute to the spiking credit bonds spreads.

The ever-growing default incidents in recent years have ignited investors' concerns about credit risks, though in our perspective, these temporary market disruptions are inevitable pains that China has to go through towards a more market-oriented financial market. For instance, Credit Risk Mitigation Agreement (CRMA) and Credit Risk Mitigation Warrant (CRMW), which are essentially Credit Default Swaps (CDS) derivative products and initially introduced in 2010, gained their popularity following the recent wave of corporate defaults. What is more, tightened regulations by Beijing starting late 2017 on Wealth Management Plans, together with the government-led deleveraging campaign, further curbed the inflow of funds towards corporate bonds, especially those lower-rated ones on the edge of defaulting. This worsens their default probability and, in turn, making institutional investors even more cautious in purchasing the bonds newly issued by these firms. This type of negative rollover spiral due to market liquidity dry-up is responsible for the explosion of bond defaults in early $2018 .{ }^{20}$

\subsection{Bond Default Cases, Bankruptcy, and Post-default Recovery ${ }^{21}$}

This section discusses several recent prominent bond default cases in China. These cases also illustrate the underdeveloped legal environment in China, and the uncertain bankruptcy litigation procedures faced by bond investors when seeking recovery of their defaulted bonds.

\footnotetext{
${ }^{20}$ The defaulted companies in 2018 are having much stronger balance sheets than those defaulted in 2016-17, in terms of simple financial ratios like book leverage and interest coverage cited from some industry report by China International Trust Investment Corporation (CITIC) Securities.

${ }^{21}$ We thank Andrew Levin’s contribution to this section, which is heavily drawn from his term paper for the MBA class “Chinese Economy and Financial Market” in Chicago Booth taught by Zhiguo He in the winter quarter of 2018.
} 
Before delving into these detailed default cases, we provide a bit background on China's bankruptcy laws. A well-functioning bankruptcy law, including restructuring and reorganization, is important to business owners and investors. There are three types of bankruptcy proceedings: liquidation, settlement, and reorganization. China introduced the Enterprise Bankruptcy Law in 1986, though it is the 2006 reform that led China on a path towards convergence with international practice, with the inclusion of reorganization proceedings that are similar in nature to Western bankruptcies and restructurings.

Despite these positive changes, many concerns about implementation of the bankruptcy code remain nowadays due to lack of legal infrastructure, a disparate court system, and potentially ongoing moral hazard issues particularly related to SOEs. Besides, key differences remain between China and U.S./U.K. bankruptcy proceedings including a lack of Debt-in-Possession financing in China and the inability of creditors to propose a plan of reorganization.

\section{Shanghai Chaori Solar (上海超日)}

On March 4, 2014, Shanghai Chaori Solar, a privately-held solar equipment producer, announced that it would not meet interest payments on its 1 billion RMB bond issued in the exchange market. This was the first case of a publicly issued bond default in China. Despite the small bond size, this event was still a big deal to market participants because until that point it seemed as though the government would support struggling companies to keep defaults from occurring.

What happened in the end? In October 2014, a number of state-owned entities, mostly asset management companies (including China Great Wall Asset Management), worked together to provide loans and guarantees to Shanghai Chaori Solar. Under this help, Shanghai Chaori Solar fully repaid its past due principal and interest. This led analysts to say that this action was "good for investors but bad for credit pricing," as many practitioners argue that real credit defaults in China would reduce the guise of moral hazard in the economy and therefore lead the country to develop a healthier credit market. 


\section{Baoding Tianwei (保定天威)}

On April 21, 2015, Baoding Tianwei missed an interest payment on its 1.5 billion medium-term note. While this was the third onshore default in 13 months, the Baoding Tianwei default was meaningful in that it was the first for a 100\% state-owned enterprise. Baoding Tianwei had been established in 1995 as a unit of China South Industries Group, a military and defense company wholly owned by State-owned Assets Supervision and Administrative Commission (SASAC, 国资委). As such, the default of Baoding on 1.5 billion RMB of bonds (and later up to 4.5 billion RMB) was a meaningful shift in the government's stance towards SOEs. With over $90 \%$ of corporate bonds outstanding issued by SOEs, this was an important event in China's history. While the company's issues have yet to be resolved, it has since defaulted on additional debt outstanding and formally filed for bankruptcy. Jin, Wang, Zhang (2018) study this historical event to estimate the value of implicit guarantee in Chinese bond market.

\section{Sichuan Coal Industry Group (川煤集团)}

Sichuan Coal Industry Group, a local SOE, defaulted on its 1.05 Billion bond principal in June 2016. The local government quickly stepped in and provided emergency financing to the company who was then able to pay back bondholders in full. The company repaid investors with entrusted loans from the stateowned Sichuan Provincial Investment Group which obtained the loans from the Bank of Communications and other state-owned banks. Then, in December 2016, only 5 months after paying bondholders in full, Sichuan Coal defaulted again, as its operating metrics could nowhere near support its debt-load. The government's intervention in June/July 2016 had only “thrown good money after bad.” This example highlighted the uncertain process with which different defaults were handled in China.

\section{Guangxi Non-Ferrous Metal (广西有色)}

Another SOE bond default involves Guangxi Non-Ferrous Metal (GNFM), which is owned by the Guangxi provincial government. This case is unique because of the sheer size of GNFM's capital structure 
that includes 14.5 billion in debt outstanding. Also, after GNFM failed to propose a reorganization plan within six months after a court order, the restructuring period was brought to a close and the company declared bankrupt; GNFM became the first interbank bond issuer to declare bankrupt.

The failure of the plan of reorganization was said to stem from the court-appointed administrator who did not properly take creditor demands into account when forming the plan. In reaction to the proposed plan, one lawyer said "bankruptcy law in China is not aligned with the interests of the creditors, and the fact that the administrators are always appointed by a court raises the suspicion that there is government intervention.” 22 But one has to see the positive side of this case, in which the Chinese government did not intervene to provide financing to GNFM or have an government-backed asset management companies do so. This shows that the 'implicit guarantee' is fading away and the Chinese government is letting the Enterprise Bankruptcy Law and the markets determine the fate of an increasing number of private enterprises and SOEs. ${ }^{23}$

\section{Dongbei Steel (东特钢)}

In a precedent-setting case for the Chinese bond market, Dongbei Steel agreed to a restructuring plan in 2017 to settle with its outstanding creditors. Dongbei Special Steel Group is a company majority-owned by the Liaoning provincial government and defaulted on its 0.8 billion RMB commercial paper in March 2016. In August 2017, creditors mostly agreed to haircuts in order to settle the first restructuring of an

\footnotetext{
22 Yu, Zhang and Tongjian, Dong. Guangxi Nonferrous’ Creditors Veto Insolvency Plan. Caixin, November 2, 2016. The lawyer was reacting to a plan of reorganization that would have seen creditors receive under $20 \%$ recoveries and a large amount of equity in lieu of their claims. Instead, the firm was placed in involuntary liquidation, being forced to start selling everything from equity ownership of subsidiaries to office supplies and desk chairs.

${ }^{23}$ Guangxi Nonferrous Metals is China’s first interbank bankruptcy. South China Morning Post, September 20, 2016.
} 
onshore bond default in China. The plan, which involves restructuring of 45.6 billion RMB, called for the following:

- $\quad$ Creditors owed less than 500,000 RMB are repaid in full; ${ }^{24}$

- $\quad$ Non-financial creditors and bondholders owed more than 500,000 RMB could elect for a one-time cash payment of $22.09 \%$ of the amount owed or have their bonds converted into equity;

- $\quad$ Financial creditors owed more than 500 thousand RMB converted to equity;

- $\quad$ Two strategic investors would inject a combined 5.5 billion RMB into the company in exchange for a 53\% equity stake in the company. Creditors convert into the remaining $47 \%$ of the equity.

As the first market-led restructuring, Dongbei presented an important test case for future progress in corporate bankruptcy procedures. It sets precedents akin to restructurings in the U.S. and the U.K. While this could increase overall default rates in China, it could greatly improve economy efficiency and overall dynamism. ${ }^{25}$

We close this section by highlighting that "government-led/coordinated solutions," especially by local governments, are one of the most prominent Chinese characteristics when dealing with defaulted bonds. For economic or political reasons, Chinese local governments often rescue failing firms by either issuing relevant guidance documents, or pushing other healthy local SOEs or financial institutions to inject capital. However, local governments do not have unlimited resources. The wave of breaking “implicit guarantees”

\footnotetext{
${ }^{24}$ The cut-off of 500,000 RMB below which receiving the full repayment is likely due to the deposit insurance in China implemented in 2015, which sets the limit of 500,000 RMB as well. Perhaps more importantly, it reduced the number of claimants drastically paving an easier path towards resolution.

${ }^{25}$ Goldman Sachs Research, August 10, 2017.
} 
should help local authorities to escape from the notion of unconditionally rescuing the zombie firms, and alleviate the notorious soft budget constraint problem that still looms in China's economic and financial reform today.

\section{Data Sources on Chinese Bond Markets}

We briefly summarize commonly used data sources for conducting research on China's interbank market. The data on the exchange market can be obtained from the Stock Exchanges.

\subsection{Data from Wind}

Wind Information Co. (Wind, 万得) consolidates various data sources and offers comprehensive data access to interbank bond market data. On the bond level, Wind provides data on individual bonds' characteristics and time series of daily trading. Variables of bond characteristics include but not limited to bond issuance information, issuer's financial statement information, etc. Variables of daily trading include but not limited to close clean price, dollar trading amount, etc. In addition, data on yield-tomaturity based on secondary market transactions calculated by CSDC (available from www.ChinaBond.com.cn) can also be downloaded through Wind.

On the market level, Wind aggregates individual bonds' issuance and trading information by bond category, maturity, region, rating, etc. Wind also collects information on depository market and investor composition for various bond types. Besides data on bond characteristics and trading, Wind has several special statistics on interbank market, such as bond credit risk analysis, convertible bonds, oversea bonds, open market operations, asset-backed securities, interest rate swap and derivatives, etc.

\subsection{China Foreign Exchange Trading System}

The secondary market bond trading in the interbank market is conducted through CFETS. CFETS provides several standard bond data products for practitioners and academic researchers, including bond transaction 
data aggregated at daily frequency, effective bond quote data as of the end of each trading day, interbank market spot and repo transaction aggregated at institutional category level with daily, monthly, quarterly frequency, etc. Among all standard products, the daily bond quote data and transaction by category data are proprietarily provided by CFETS and not available from other data vendor. In addition, customized data service is possible for academic research upon receiving written research proposal.

\subsection{PBC Statistic Reports}

The PBC releases various statistic reports covering the interbank market, including Financial Market Statistics, Financial Statistics Data Report, China Financial Stability Report, etc. Most the PBC statistics are available from Wind, and can be directly downloaded from the website of the PBC (under the Department of Statistics). Some reports, e.g., China Financial Stability Report, are only available in hard copy.

\subsection{Issues in Using the Interbank Market Data}

Bond data quality of commercial vendors in China is on average lower than those in the U.S. market, i.e., the TRACE dataset. Due to the complexity of the interbank market, sometimes the same variable provided by two different data sources could be inconsistent. Researchers have to dig into details of the original data description files and regulatory documents to pick the right one. Finally, researchers should pay special attention to noticeable changes in time-series variables, as the measurement of statistics changes more frequently in China than developed countries, due to volatile policy and regulatory guidelines. 
Figure 1: A Comparison of U.S. and China Bond Market Growth

Panel A: US and China Outstanding Bond Balance as \% of GDP

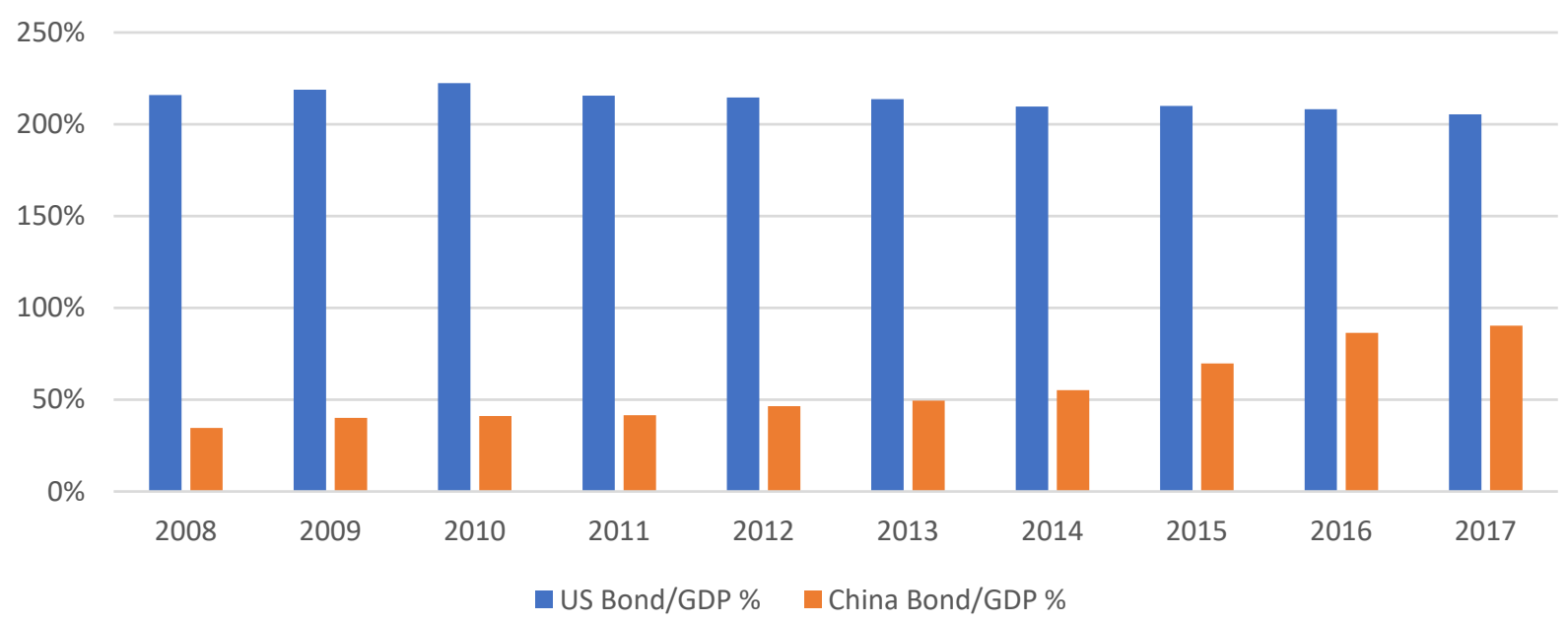

\section{Panel B: US and China Outstanding Bond Balance as \% of Stock Market Capitalization}

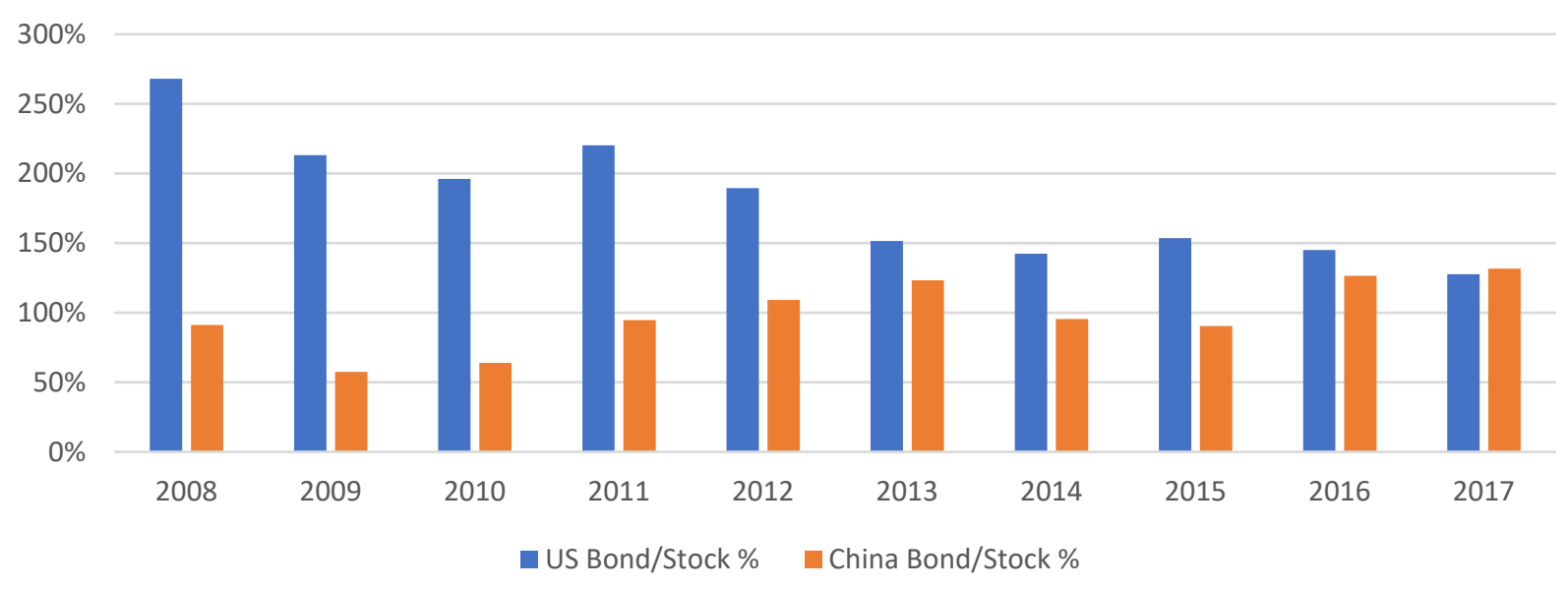

Data Source: China: Wind Bond Overview

US: SIFMA US Bond Market Issuance and Outstanding (www.sifma.org/resources/research/us-bond-market-issuance-and-outstanding/)

GDP: China: Wind Macroeconomic Database

US: FRED Economic Data (https://fred.stlouisfed.org/series/GDP)

We use nominal GDP because outstanding numbers are calculated using market value of bonds (also nominal).

Stock Market Capitalization: China: Shanghai Stock Exchange (SSE) + Shenzhen Stock Exchange (SZSE)

US: World Bank Database. (https://data.worldbank.org/indicator/CM.MKT.LCAP.CD)

All numbers are as of the end of each year. 
Figure 2: Chinese Interbank Market Investor Structure, 2018

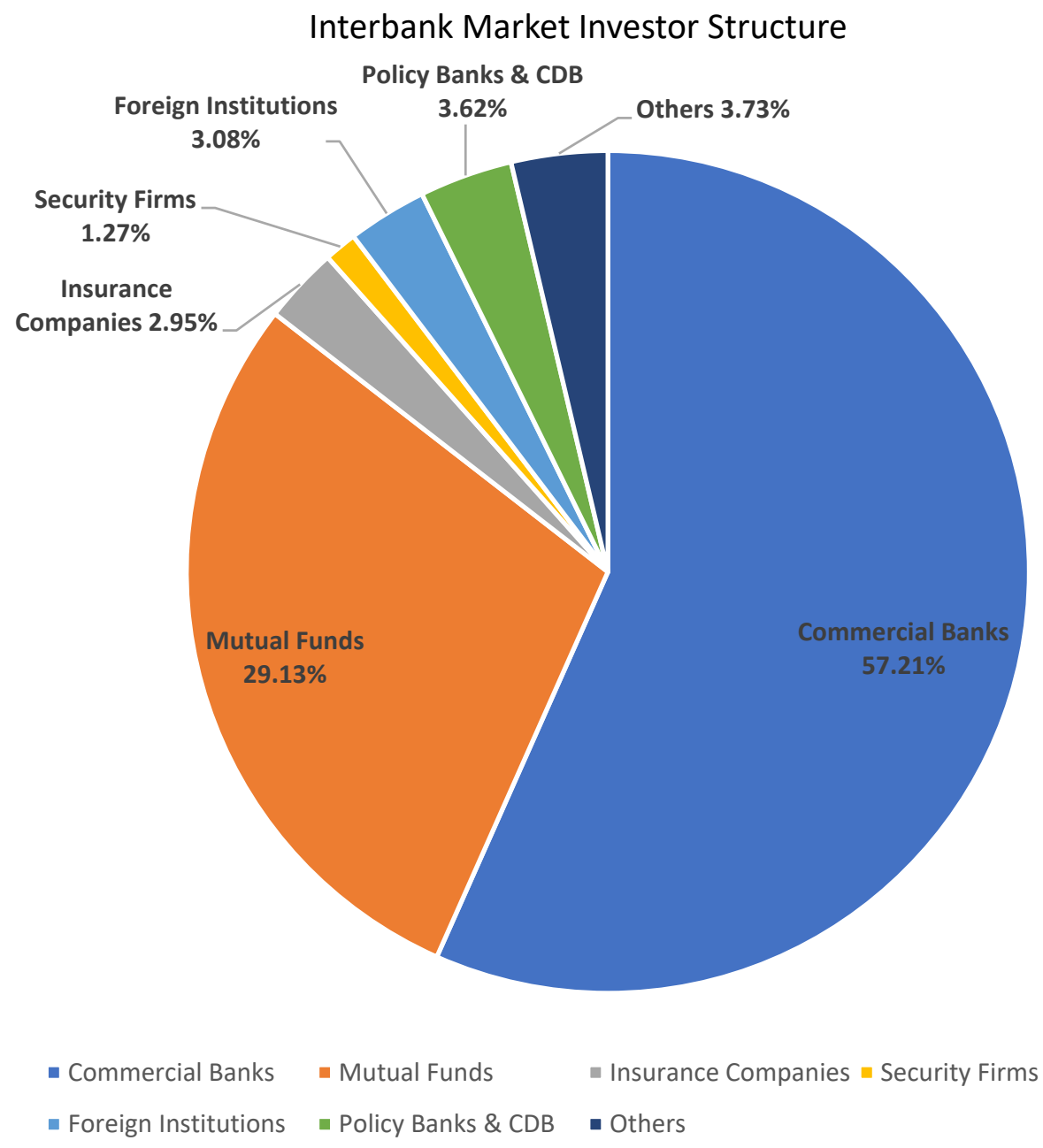

Data source: CCDC: http://www.chinabond.com.cn/Channel/19012917?BBND=2017\&BBYF=12\&sPageType=2\# SHCH: http://www.shclearing.com/sjtj/tjyb/

SHCH only reports investor structure information for major bond securities. As a result, the aggregated investment amount is lower than the total outstanding balance. We adjust the outstanding balance for each investor while maintaining their corresponding shares.

The numbers are as of 12/31/2018. 
Figure 3: Outstanding Bond Balance in Chinese and U.S., 2008 - 2017

Panel A: 2008-2017 Chinese Outstanding Bond Balance (in Trillions RMB)

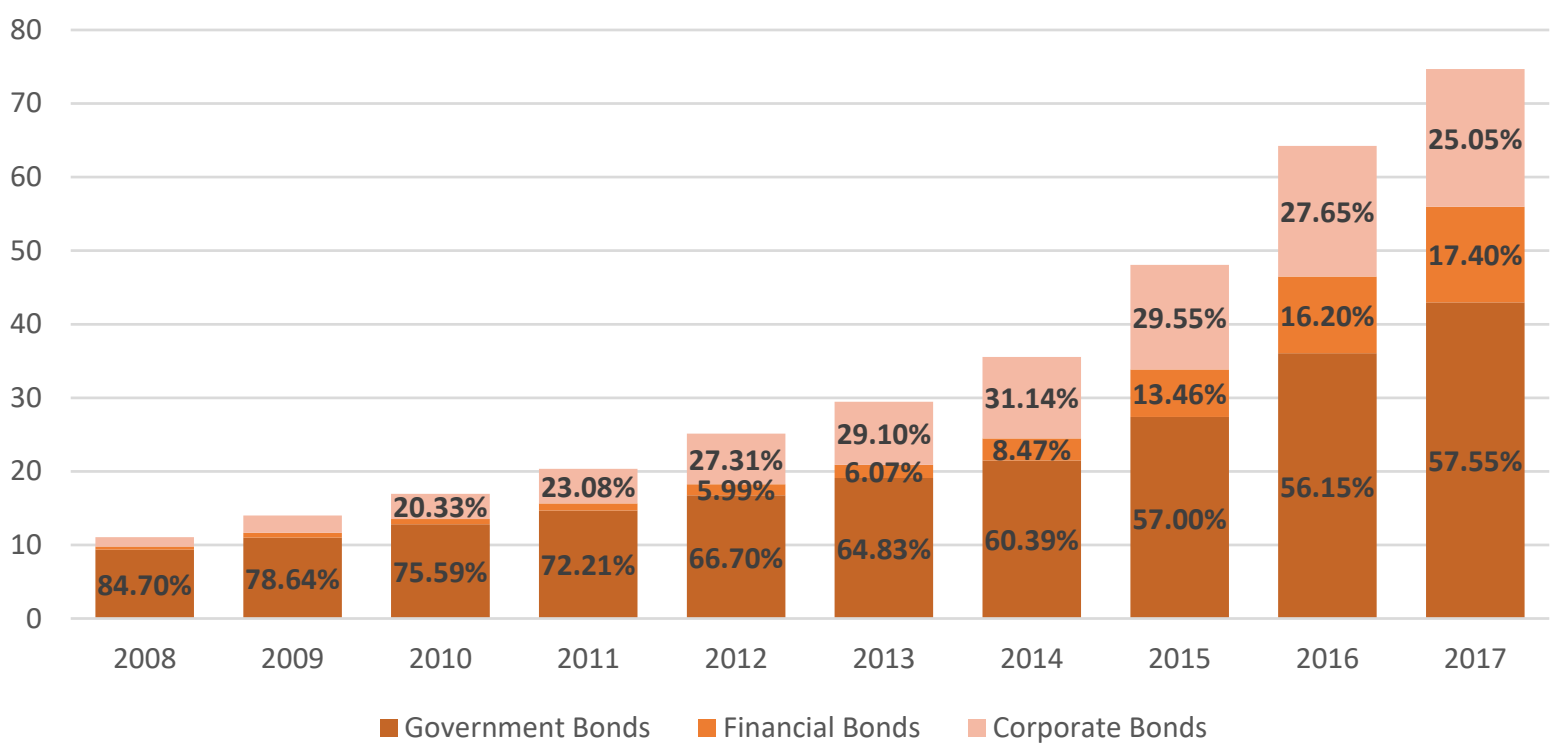

Panel B: 2008-2017 US Outstanding Bond Balance (in Trillions \$)

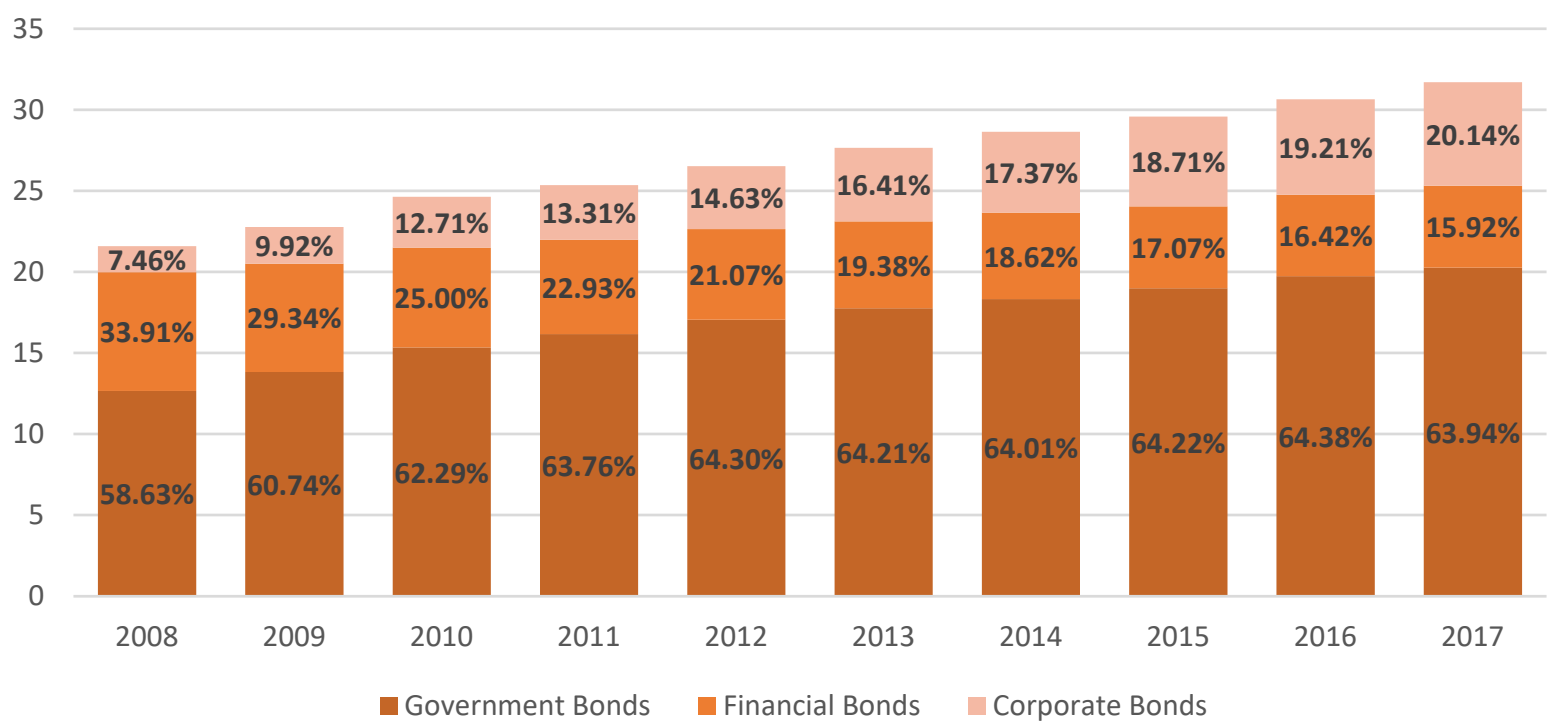

Data source: China: Wind Bond Overview

We reorganize bond types into the three categories as in Section 2.2 year by year.

US: Government/Non-government Bonds: SIFMA US Bond Market Issuance and Outstanding (see Figure 1 footnote)

Financial Bonds: Financial Accounts of the United States (https://www.federalreserve.gov/releases/z1/current/): Domestic Financial Assets (L.108): Financial Bonds = Open Market Paper + Corporate and Foreign Bonds

Corporate Bonds = Non-Government Bonds (from SIFMA) - Financial Bonds (from the Fed)

We exclude mortgage-related (agency- and GSE-backed) securities, which is a significant part of US bond market, in calculating the composition of US bonds, because there are no comparable mortgage-related securities in Chinese bond markets.

All numbers are as of the end of each year. 
Figure 4: Composition of Bonds in Chinese Interbank and Exchange market, 2018

Panel A: 2018 Chinese Interbank Market Bond Composition

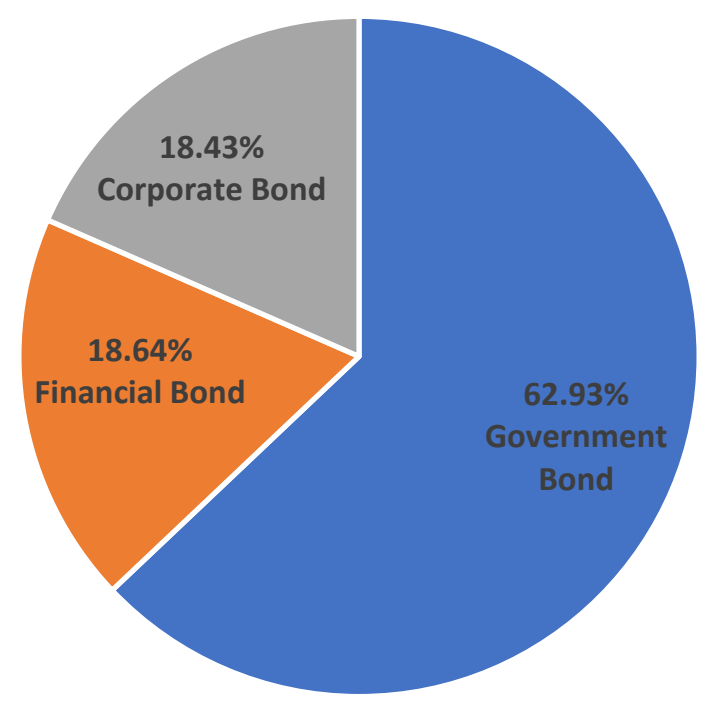

\section{Panel B: 2018 Chinese Exchange Market Bond Composition}

$10.29 \%$

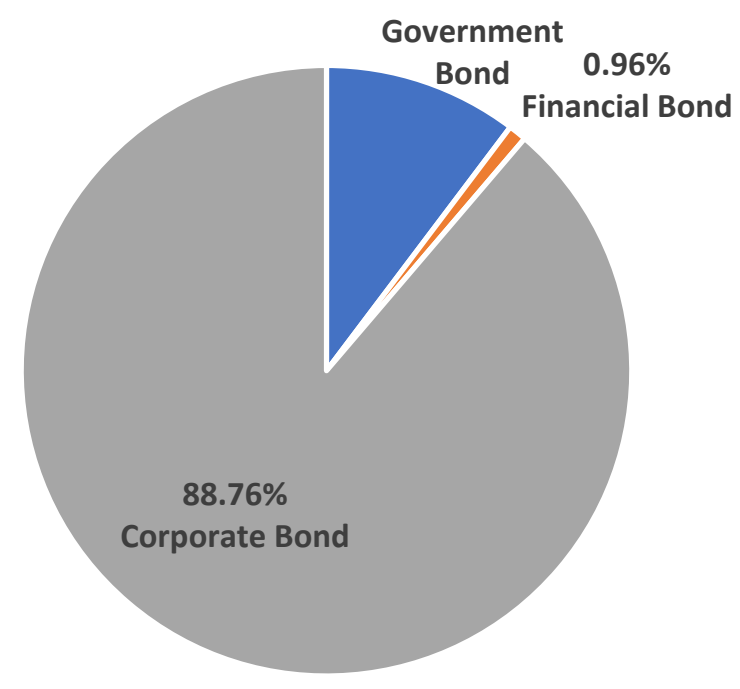

Data source: Interbank: China Central Depository \& Clearing (CCDC) + Shanghai Clearing House (SHCH)

(CCDC: http://www.chinabond.com.cn/Channel/19012917?BBND=2017\&BBYF=12\&sPageType=2\#; SHCH:

http://www.shclearing.com/sjtj/tjyb/)

Exchange: China Securities Depository and Clearing Corp. (CSDC) (http://www.chinaclear.cn/zdjs/tjyb1/center_tjbg.shtml)

For CCDC, we only include bonds in the interbank market, the OTC market, and the Free Trade Zone market that are in custody of CCDC (i.e., excluding those bonds that dual-listed in the exchange market).

All numbers are as of 12/31/2018. 
Figure 5: China's Interbank and Exchange Market Spot Transaction

Panel A: Spot Transaction: Number of Trades in Millions

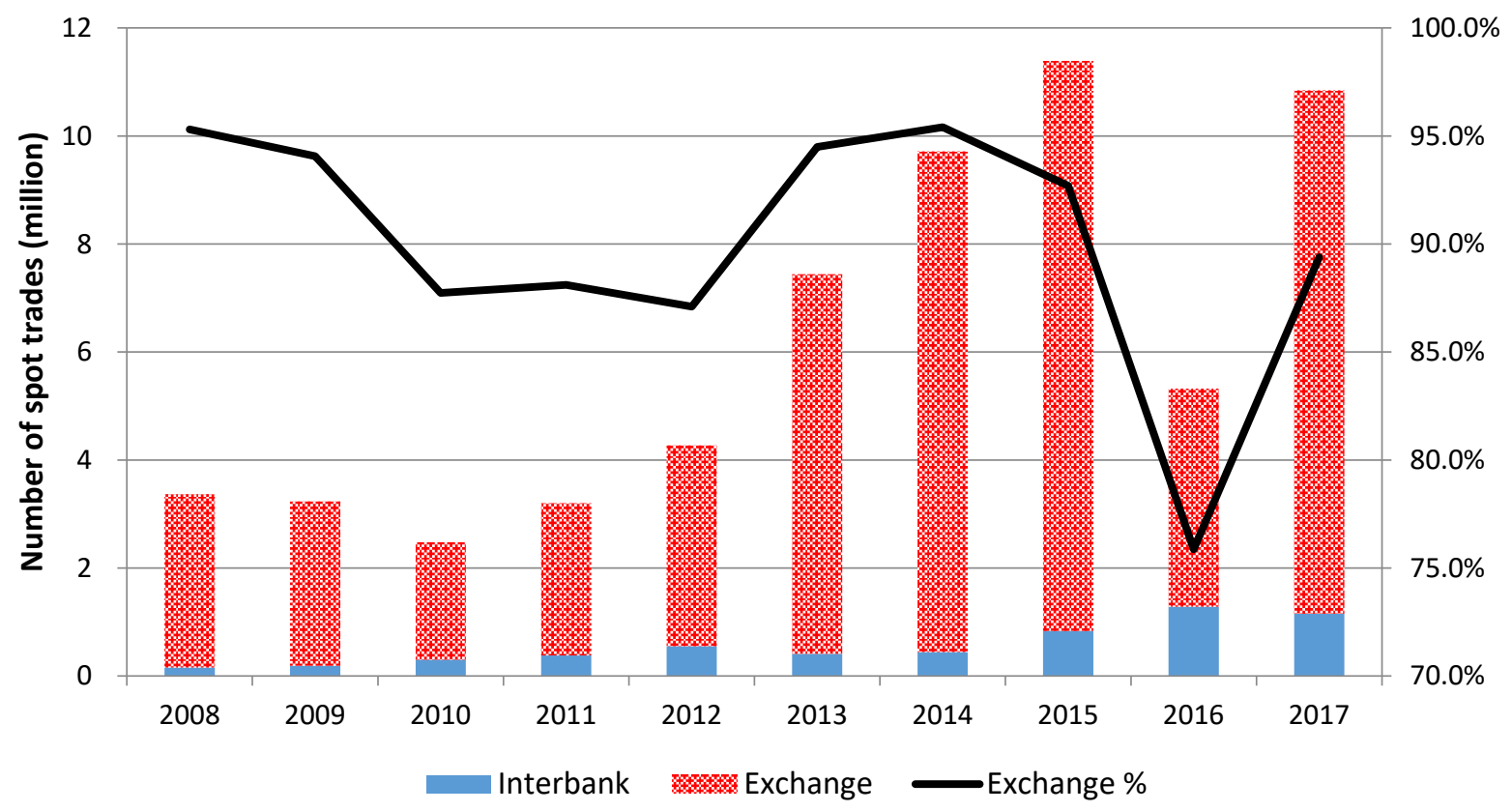

Panel B: Spot Transaction: Volume in Trillion RMB

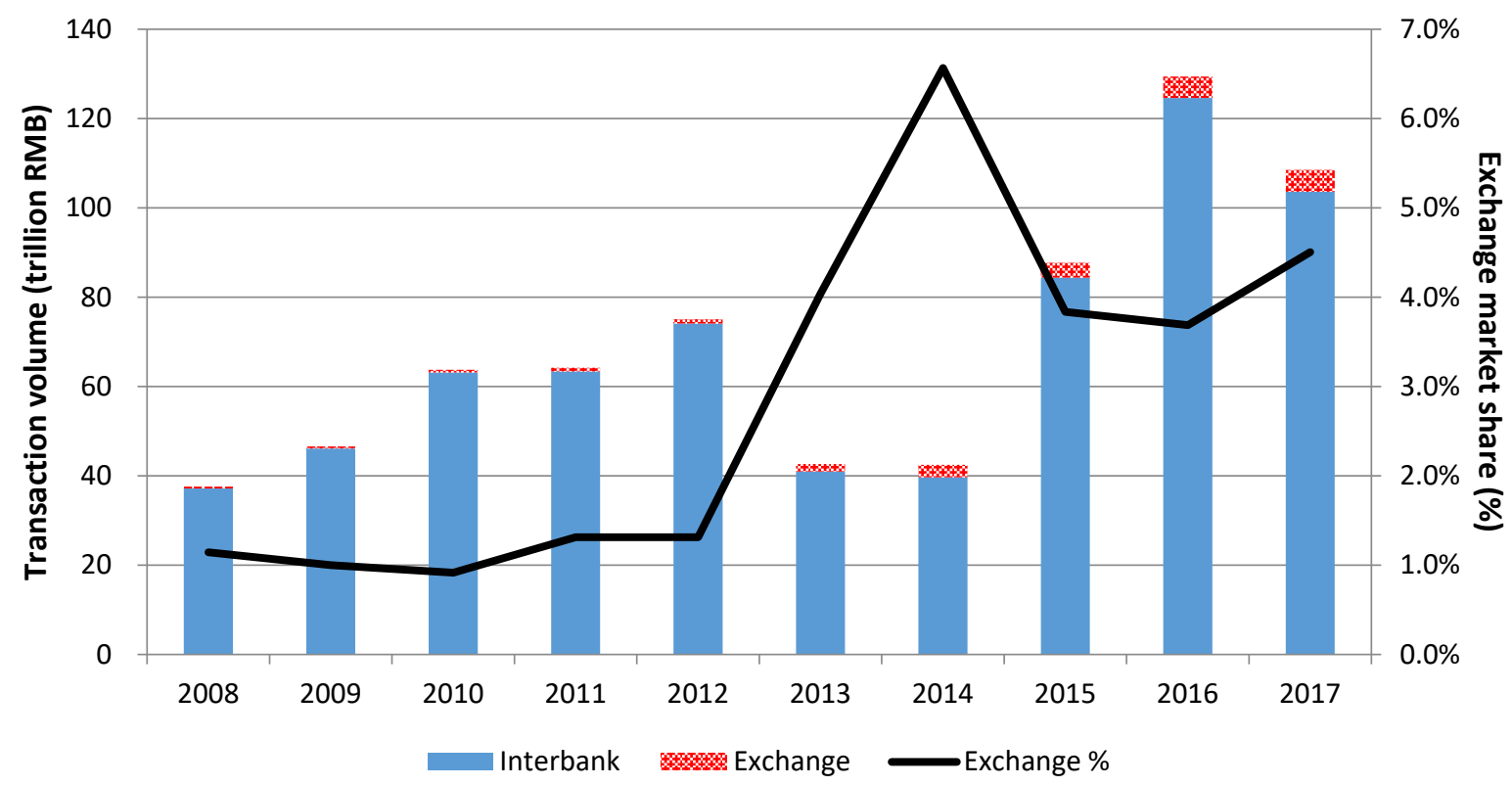

These figures plot China’s interbank and exchange market spot transaction RMB volume from 2008 to 2017.

Panel A plots number of trades for spot transactions in these two markets. Panel B plots spot transaction RMB volume of all bonds on the interbank and exchange markets. Data on the interbank-market transactions are from China Foreign Exchange Trade System and data on the exchange-market transactions are from the Statistics Annuals of Shanghai exchange and Shenzhen exchange. 
Figure 6: Treasury and CDB Yield Curve in Different Maturities

Treasury and CDB Yield in Different Maturities (in \%)

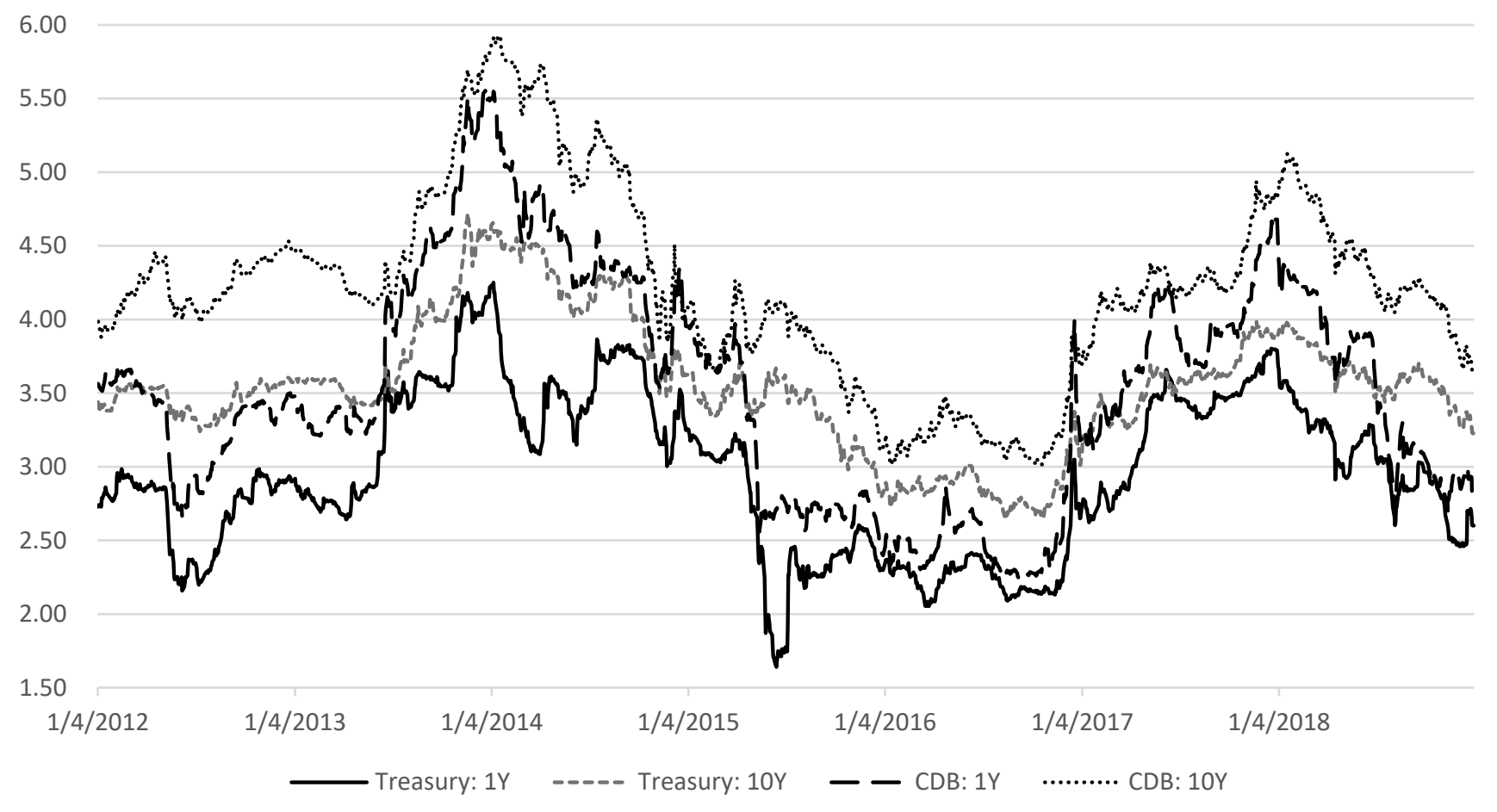

Data Source: Wind Database Bond Yield Analysis 
Figure 7: Rating Distribution by Outstanding Bond Balance \& Number of Issuers - 2018

\section{Panel A: Non-Financial Corporate Issuer Ratings by Outstanding Bond Balance - 2018/12/31}

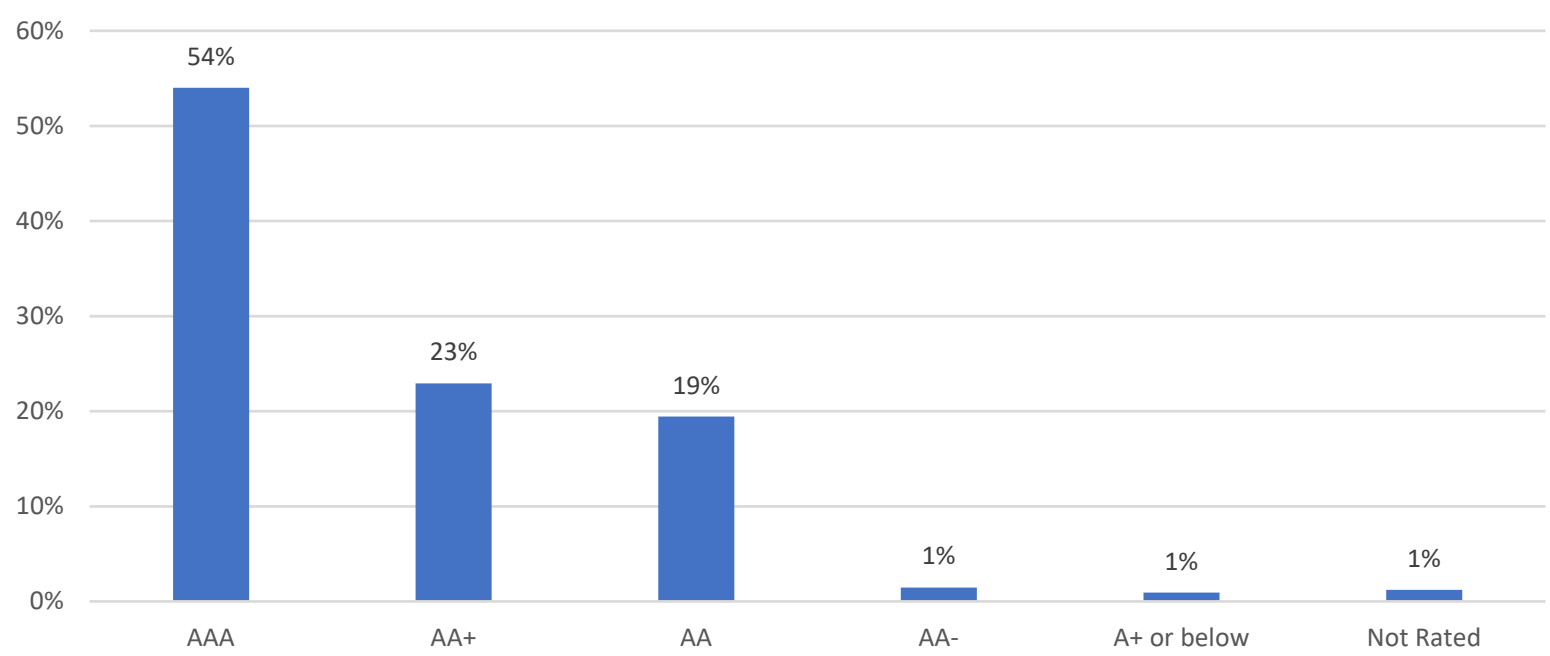

Panel B: Non-financial Corporate Issuer Ratings by Number of Issuers $2018 / 12 / 31$

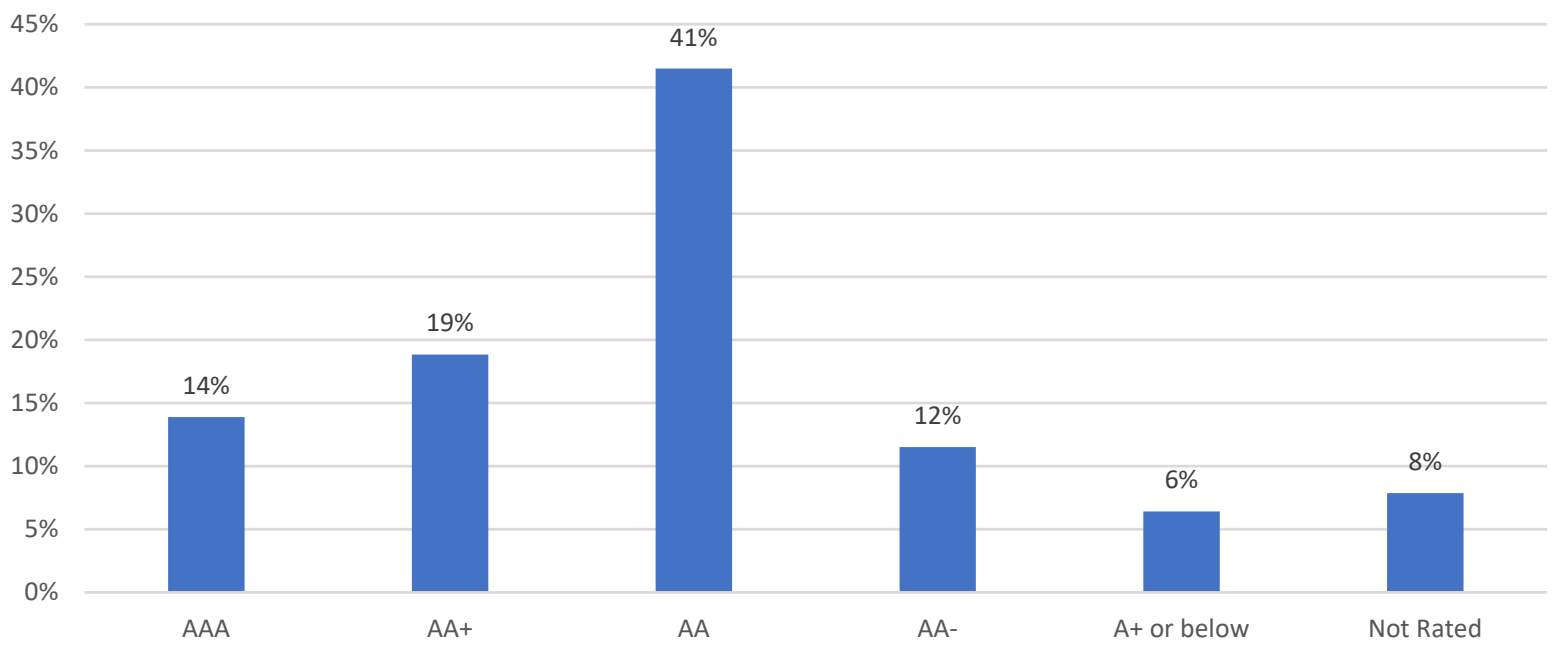

Data Source: Wind Database

We sum up the outstanding bond amounts and count the number of issuers for each rating class using all corporate bonds available on 12/31/2018 (see Table 1 for our definition of corporate bond categories). We exclude all Asset-Backed Securities (ABS, 资产支持证券) in the corporate bond category. Since the "issuer" performs an "underwriter" role to these ABS securities, the issuer ratings do not represent the creditworthiness of the security. 
Figure 8: Number and Amount of Defaults by Year

Panel A: Defaulted Bonds, number (left) and amount (billions RMB, right)

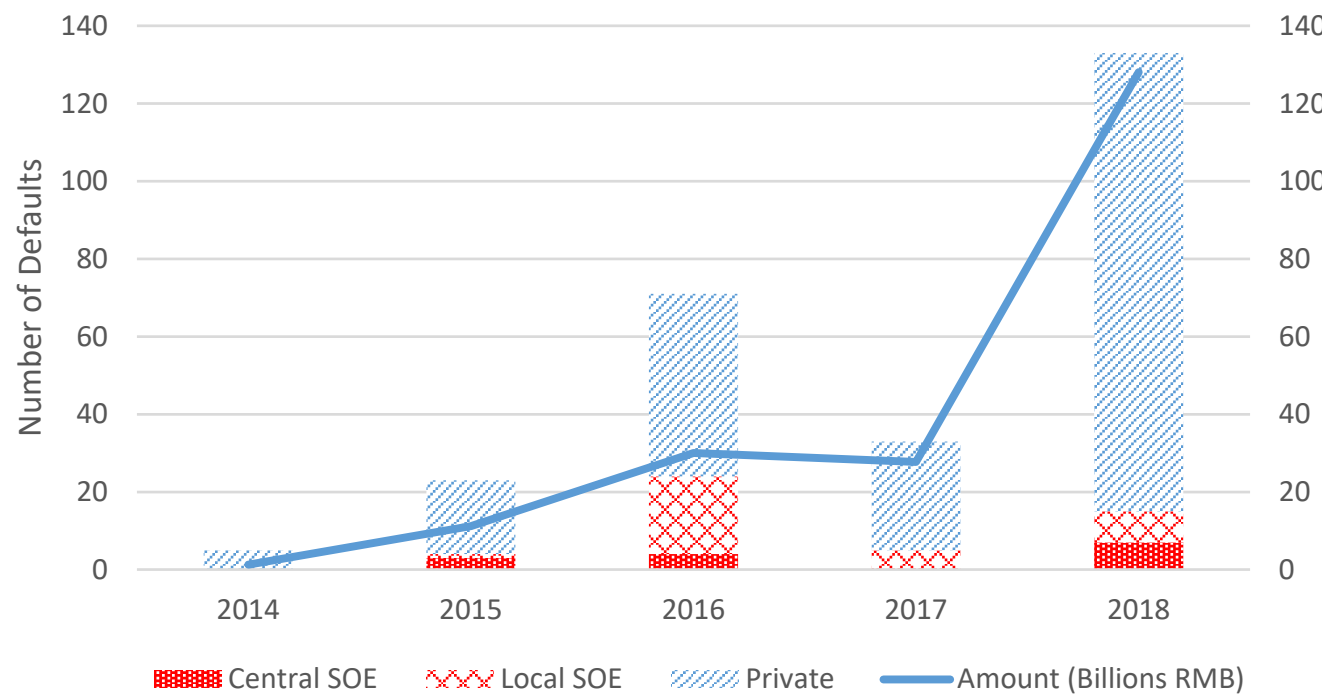

Panel B: Defaulted Bonds, number (left) and amount (right) as percentage of total corporate bonds

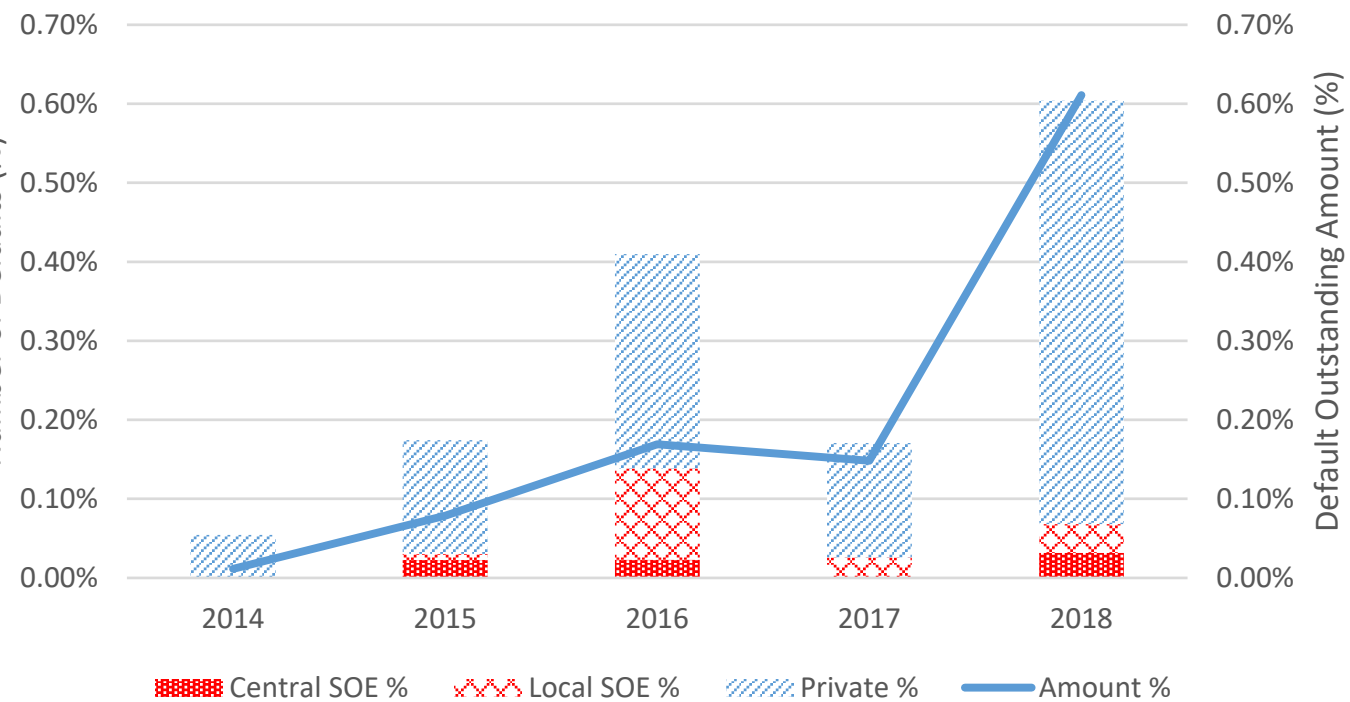

Data Source: Wind Database Credit Bond Research (Defaulted Bond Summary Table and Issuers First Default Table)

We report the number and the amount of defaulted bonds, both in amounts (Panel A) and percentage (Panel B, relative to all corporate bonds). We count the principal value of defaulted bonds only (excluding interests). We only keep one record for duplicate events caused by defaulted dual-listed bonds, except Jiangquan and Hongchang Gas (for these two issuers, the two records on the same date are separate default events: one for principal and the other for interest).

Private firms include all firms in our sample that are not SOEs.

All numbers are as of the end of each year. 
Figure 9: Credit Spreads of Enterprise Bonds in China across Ratings

Credit Spreads of Enterprise Bonds in China Across Ratings (in \%)

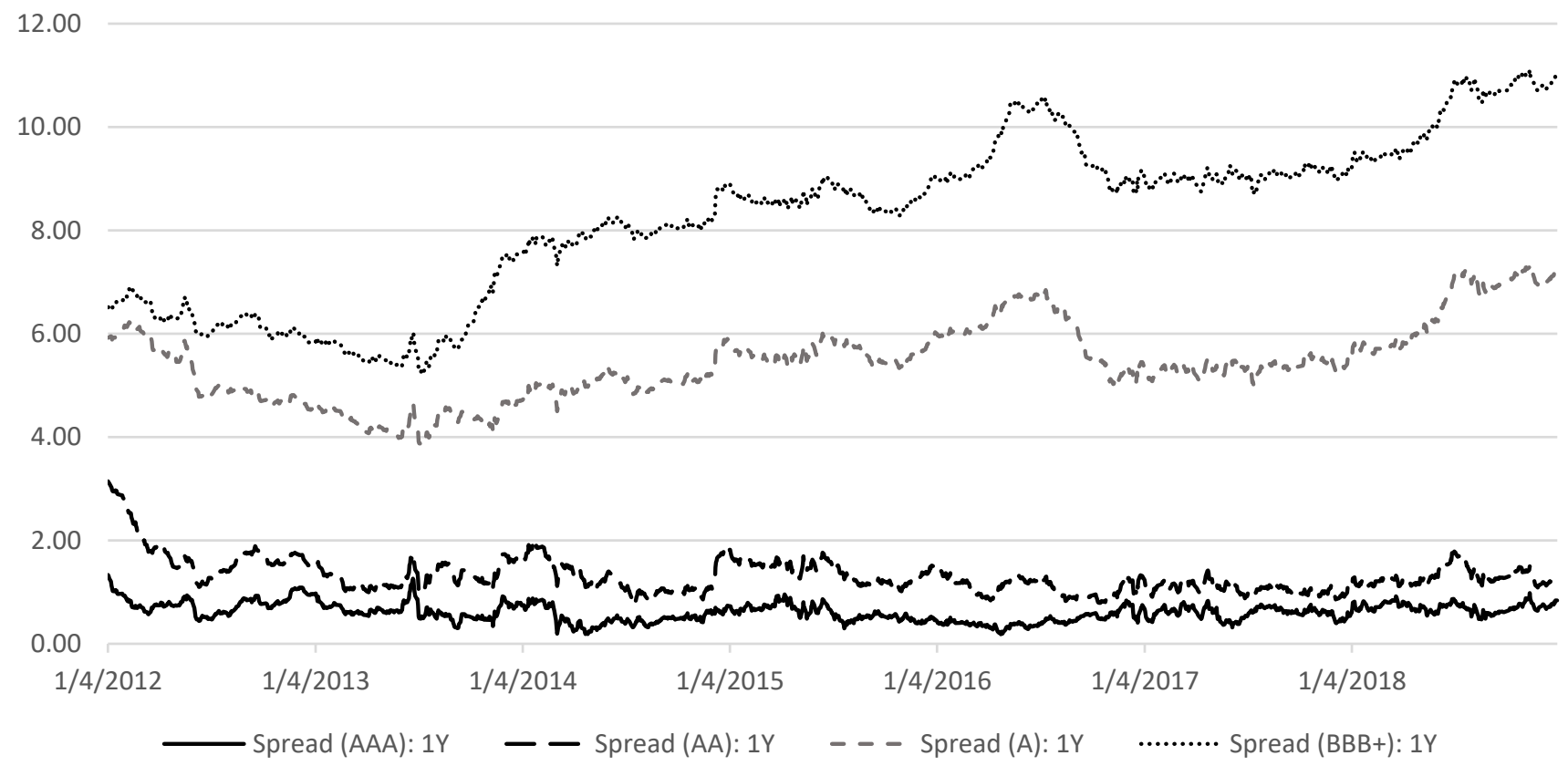

Data source: Wind Database Bond Yield Analysis

This figure depicts the 1-year credit spreads of bonds with different ratings (AAA, AA, A, BBB+) from start of 2012 to 2018 . Credit spread is the bond yield minus the corresponding CDB spot yield for each rating. 
Table 1: Outstanding Bond Balance in Chinese bond markets, 2008 and 2018

\begin{tabular}{|c|c|c|c|c|c|}
\hline 2008 & Market & $\begin{array}{r}\text { Outstanding } \\
\text { (Number) }\end{array}$ & $\begin{array}{r}\text { Outstanding (\% } \\
\text { Number) }\end{array}$ & $\begin{array}{r}\text { Outstanding (RMB } \\
\text { Billions) } \\
\end{array}$ & $\begin{array}{r}\text { Outstanding (\% } \\
\text { RMB) } \\
\end{array}$ \\
\hline Total & & 1,211 & 100.00 & $11,066.91$ & 100.00 \\
\hline Government Bonds & Interbank, Exchange, OTC & 408 & 33.69 & $9,373.55$ & 84.70 \\
\hline Treasury Bonds & Interbank, Exchange, OTC & 149 & 12.30 & $5,478.32$ & 49.50 \\
\hline Policy Bank Bonds & Interbank, Exchange & 234 & 19.32 & 3,698.33 & 33.42 \\
\hline Other Government Bonds & Interbank, Exchange & 25 & 2.06 & 196.90 & 1.78 \\
\hline Financial Bonds & Interbank & 109 & 9.00 & 424.94 & 3.84 \\
\hline Other Financial Bonds & Interbank & 109 & 9.00 & 424.94 & 3.84 \\
\hline Corporate Bonds & Interbank, Exchange & 694 & 57.31 & $1,268.42$ & 11.46 \\
\hline Enterprise Bonds & Interbank, Exchange & 272 & 22.46 & 485.37 & 4.39 \\
\hline Exchange-Traded Corporate Bonds & Exchange & 20 & 1.65 & 40.00 & 0.36 \\
\hline Medium-Term Notes & Interbank & 39 & 3.22 & 167.20 & 1.51 \\
\hline Commercial Papers & Interbank & 256 & 21.14 & 419.31 & 3.79 \\
\hline Asset-Backed Securities & Interbank & 68 & 5.62 & 49.26 & 0.45 \\
\hline Others & Exchange & 39 & 3.22 & 107.29 & 0.97 \\
\hline 2018 & Market & $\begin{array}{r}\text { Outstanding } \\
\text { (Number) }\end{array}$ & $\begin{array}{r}\text { Outstanding (\% } \\
\text { Number) }\end{array}$ & $\begin{array}{r}\text { Outstanding (RMB } \\
\text { Billions) } \\
\end{array}$ & $\begin{array}{r}\text { Outstanding (\% } \\
\text { RMB) } \\
\end{array}$ \\
\hline Total & & 42,423 & 100.00 & $85,587.11$ & 100.00 \\
\hline Government Bonds & Interbank, Exchange, OTC & 4,828 & 11.38 & $48,836.20$ & 57.06 \\
\hline Treasury Bonds & Interbank, Exchange, OTC & 278 & 0.66 & $14,831.84$ & 17.33 \\
\hline Municipal Bonds & Interbank, Exchange & 4,064 & 9.58 & $18,071.05$ & 21.11 \\
\hline Policy Bank Bonds & Interbank, Exchange & 336 & 0.79 & $14,323.81$ & 16.74 \\
\hline Other Government Bonds & Interbank, Exchange & 150 & 0.35 & $1,609.50$ & 1.88 \\
\hline Financial Bonds & Interbank & 15,717 & 37.05 & $15,784.06$ & 18.44 \\
\hline Negotiable Certificates of Deposit & Interbank & 14,218 & 33.51 & $9,851.43$ & 11.51 \\
\hline Other Financial Bonds & Interbank & 1,499 & 3.53 & $5,932.63$ & 6.93 \\
\hline Corporate Bonds & Interbank, Exchange & 21,878 & 51.57 & $20,966.84$ & 24.50 \\
\hline Enterprise Bonds & Interbank, Exchange & 2,550 & 6.01 & $2,568.20$ & 3.00 \\
\hline Exchange-Traded Corporate Bonds & Exchange & 5,252 & 12.38 & $5,820.43$ & 6.80 \\
\hline Medium-Term Notes & Interbank & 4,309 & 10.16 & $5,653.90$ & 6.61 \\
\hline Commercial Papers & Interbank & 1,894 & 4.46 & $1,923.71$ & 2.25 \\
\hline Asset-Backed Securities & Interbank & 5,136 & 12.11 & $2,643.21$ & 3.09 \\
\hline Private Placement Notes & Interbank & 2,437 & 5.74 & $1,943.84$ & 2.27 \\
\hline Other Corporate Bonds & Exchange & 300 & 0.71 & 413.54 & 0.48 \\
\hline
\end{tabular}

Data source: Wind Bond Overview

We reorganize the original dataset based on the three categories in Section 2.2: Government Bonds, Financial Bonds, and Corporate Bonds.

All numbers are as of 12/31/2008 and 12/31/2018. 
Table 2: Chinese Bond Issuance, Outstanding and Spot Transaction Volume by Types, 2018

\begin{tabular}{|c|c|c|c|c|c|c|c|}
\hline 2018 & Market & $\begin{array}{r}\text { Issuance } \\
\text { (Billions RMB) }\end{array}$ & $\begin{array}{r}\text { Issuance } \\
(\%) \\
\end{array}$ & $\begin{array}{r}\text { Outstanding } \\
\text { illions RMB) }\end{array}$ & $\begin{array}{r}\text { Outstanding } \\
(\%) \\
\end{array}$ & $\begin{array}{r}\text { Transaction Volume } \\
\text { (Billions RMB) }\end{array}$ & Turnover \\
\hline Total & & $43,771.07$ & 100.00 & $85,587.11$ & 100.00 & $149,940.81$ & 1.87 \\
\hline Government Bonds & Interbank, Exchange, OTC & $11,484.24$ & 26.24 & $48,836.20$ & 57.06 & $74,083.08$ & 1.61 \\
\hline Treasury Bonds & Interbank, Exchange, OTC & $3,601.10$ & 8.23 & $14,831.84$ & 17.33 & $18,743.05$ & 1.33 \\
\hline Municipal Bonds & Interbank, Exchange & $4,165.17$ & 9.52 & $18,071.05$ & 21.11 & 4,349.93 & 0.27 \\
\hline Policy Bank Bonds & Interbank, Exchange & $3,464.98$ & 7.92 & $14,323.81$ & 16.74 & $50,386.57$ & 3.64 \\
\hline Other Government Bonds & Interbank, Exchange & 253.00 & 0.58 & $1,609.50$ & 1.88 & 603.53 & 0.39 \\
\hline Financial Bonds & Interbank & 22,879.49 & 52.27 & $15,784.06$ & 18.44 & $57,048.47$ & 3.96 \\
\hline Negotiable Certificates of Deposit & Interbank & $21,098.56$ & 48.20 & $9,851.43$ & 11.51 & $54,863.32$ & 6.15 \\
\hline Other Financial Bonds & Interbank & $1,780.93$ & 4.07 & $5,932.63$ & 6.93 & $2,185.16$ & 0.40 \\
\hline Corporate Bonds & Interbank, Exchange & $9,407.33$ & 21.49 & $20,966.84$ & 24.50 & $18,809.26$ & 0.95 \\
\hline Enterprise Bonds & Interbank, Exchange & 241.84 & 0.55 & $2,568.20$ & 3.00 & $1,611.75$ & 0.57 \\
\hline Exchange-Traded Corporate Bonds & Exchange & $1,657.92$ & 3.79 & $5,820.43$ & 6.80 & 797.94 & 0.15 \\
\hline Medium-Term Notes & Interbank & $1,696.72$ & 3.88 & $5,653.90$ & 6.61 & $7,399.58$ & 1.41 \\
\hline Commercial Papers & Interbank & $3,127.53$ & 7.15 & $1,923.71$ & 2.25 & $7,027.94$ & 4.09 \\
\hline Asset-Backed Securities & Interbank & $2,005.60$ & 4.58 & $2,643.21$ & 3.09 & 458.96 & 0.20 \\
\hline Private Placement Notes & Interbank & 546.39 & 1.25 & $1,943.84$ & 2.27 & 929.82 & 0.47 \\
\hline Other Corporate Bonds & Exchange & 131.35 & 0.30 & 413.54 & 0.48 & 583.27 & 1.58 \\
\hline
\end{tabular}

Data source: Wind Bond Overview and Wind Bond Secondary Market Statistics.

We reorganize the original dataset based on the three categories in Section 2.2: Government Bonds, Financial Bonds, and Corporate Bonds.

We report transaction amount as spot transactions RMB volume and turnover are calculated as spot transaction amount divided by average beginning and ending balance.

All numbers are calculated as of 12/31/2018. 
Table 3: China's Corporate Bond Market Liquidity

\begin{tabular}{cccc}
\hline & $\begin{array}{c}\text { China: } \\
\text { Interbank }\end{array}$ & $\begin{array}{c}\text { China: } \\
\text { Exchange }\end{array}$ & U.S. \\
\hline ZDays & 0.88856 & 0.81326 & 0.78820 \\
ZDays $_{w / \text { trade }}$ & 0.88768 & 0.79798 & 0.70940 \\
Turnover & 0.01212 & 0.00099 & 0.00150 \\
Amihud & 0.00016 & 2.54233 & 0.48810 \\
\hline
\end{tabular}

This table, which is taken from Panel A of Table A.1 in Chen et al (2018), reports various measures of China's corporate bond market liquidity and its comparison with the U.S. bond market. ZDays is the time series average of the fraction of bonds that

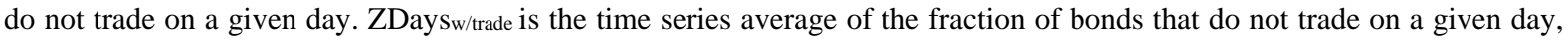
excluding bonds that do not have any single trade over the sample period. Turnover is the average daily turnover across all bond-day observations where a zero is recorded on days without trade. Amihud is the average Amihud (2002) measure across all bonds, where a bond's Amihud measure is estimated using its all non-zero daily trading observations and multiplied by $10^{6}$. The sample period is $1 / 1 / 2012$ to $12 / 31 / 2017$ for China's two markets and the sample period is $1 / 1 / 2010$ to $12 / 31 / 2014$ for the U.S. market, where the U.S. market liquidity measures are from Anderson and Stulz (2017). 
Table 4: Chinese Interbank and Exchange Market Comparison, 2018

\begin{tabular}{|c|c|c|c|}
\hline & \multicolumn{2}{|c|}{ Interbank Market } & \multirow{2}{*}{$\begin{array}{c}\text { Exchange Market } \\
\text { Exchange }\end{array}$} \\
\hline & CCDC & SHCH & \\
\hline Products & \begin{tabular}{|c|} 
Treasury Bonds, Municipal \\
Bonds, Policy Bank Bonds, \\
Central Bank Bills, \\
Enterprise Bonds, Medium- \\
Term Notes, Commercial \\
Bank Bonds
\end{tabular} & $\begin{array}{c}\text { Commercial Papers, } \\
\text { Medium-Term } \\
\text { Notes, NCDs, } \\
\text { Asset-Backed } \\
\text { Securities, etc. }\end{array}$ & $\begin{array}{c}\text { Treasury Bonds, Municipal Bonds, Policy } \\
\text { Bank Bonds, Enterprise Bonds, } \\
\text { Exchange-traded Corporate Bonds, } \\
\text { Convertible Bonds, etc. }\end{array}$ \\
\hline Investors & $\begin{array}{r}\text { Commercial Banks, Rural Cr } \\
\text { Security Firms, Insurance C } \\
\text { Funds, Foreign Instit }\end{array}$ & $\begin{array}{l}\text { redit Cooperatives, } \\
\text { Companies, Mutual } \\
\text { tutions, etc. }\end{array}$ & $\begin{array}{c}\text { Security Firms, Insurance Companies, } \\
\text { Mutual Funds, Finance Companies, } \\
\text { Individuals, Enterprises, QFIIs (excluding } \\
\text { commercial banks) }\end{array}$ \\
\hline Trade Type & Spot, Repurchase, Forwa & rard, Swap, etc. & Spot, Repurchase \\
\hline $\begin{array}{l}\text { Depository } \\
\text { Institution }\end{array}$ & $\begin{array}{l}\text { China Central Depository \& } \\
\text { Clearing Co. Ltd (CCDC) }\end{array}$ & $\begin{array}{c}\text { Shanghai Clearing } \\
\text { House }(\mathrm{SHCH})\end{array}$ & $\begin{array}{l}\text { China Security Depository \& Clearing } \\
\text { Co. Ltd (CSDC), Shanghai Stock } \\
\text { Exchange, Shenzhen Stock Exchange }\end{array}$ \\
\hline Regulator & People's Bank of Ch & hina (PBC) & China Securities Regulatory Commission \\
\hline $\begin{array}{c}\text { Outstanding } \\
\text { Balance (in } \\
\text { Trillions RMB) } \\
\end{array}$ & 56.45 & 19.93 & 9.21 \\
\hline Amount in \% & $66 \%$ & $23 \%$ & $11 \%$ \\
\hline
\end{tabular}

Data source: Market Overview: 2015 Chinese Bond Market Institutional Investor Manual by Guotai Junan Securities Outstanding Balance: CCDC: http://www.chinabond.com.cn/Channel/19012917?BBND=2017\&BBYF=12\&sPageType=2\# SHCH: http://www.shclearing.com/sjtj/tjyb/

Exchange: CSDC: http://www.chinaclear.cn/zdjs/tjyb1/center_tjbg.shtml

All numbers are as of 12/31/2018. 
Table 5: Chinese Bond Market Regulators

\begin{tabular}{|c|c|c|}
\hline \multicolumn{2}{|r|}{ Market Type } & Regulator \\
\hline \multicolumn{2}{|r|}{ Interbank Bond Market } & PBC \\
\hline \multicolumn{2}{|r|}{ Exchange Bond Market } & CSRC \\
\hline \multicolumn{2}{|r|}{ Bond Type } & Regulator \\
\hline \multirow{2}{*}{ Government Bonds } & Treasury Bonds & PBC, MOF, CSRC \\
\hline & Central Bank Bills, Policy Bank Bonds & PBC \\
\hline \multirow{3}{*}{ Financial Bonds } & Special Financial Bonds, & PBC \\
\hline & $\begin{array}{l}\text { Commercial Bank Bonds, } \\
\text { Non-Bank Financial Bonds, }\end{array}$ & CBRC, PBC \\
\hline & $\begin{array}{c}\text { Securities Firm Bonds, Securities Firms } \\
\text { Commercial Papers }\end{array}$ & PBC, CSRC \\
\hline \multirow{7}{*}{ Corporate Bonds } & $\begin{array}{l}\text { Commercial Papers, Medium-Term Notes, } \\
\text { Private Placement Notes }\end{array}$ & NAFMII \\
\hline & Asset-Backed Securities & CBRC, PBC \\
\hline & Enterprise Bonds & $\mathrm{BC}, \mathrm{CSRC}$ \\
\hline & International Institution Bonds & PBC, MOF, NDRC, CSRC \\
\hline & Convertible Bonds & PBC, CSRC \\
\hline & Exchange-Traded Corporate Bonds & CSRC \\
\hline & $\begin{array}{l}\text { Privately Placed Small and Medium Enterprise } \\
\text { Notes }\end{array}$ & $\begin{array}{l}\text { Shanghai and Shenzhen Stock } \\
\text { Exchange }\end{array}$ \\
\hline
\end{tabular}

Data source: China's domestic bond market: The Next Financing Engine by Goldman Sachs Global Market Research, 2015

CBRC: China Banking Regulatory Commission (中国银行业监督管理委员会)

CSRC: China Securities Regulatory Commission (中国证券监督管理委员会)

MOF: Ministry of Finance (中华人民共和国财政部)

NAFMII: National Association of Financial Market Institutional Investors (中国银行间市场交易商协会)

NDRC: National Development \& Reform Commission (国家发展和改革委员会)

PBC: People’s Bank of China (中国人民银行) 
Table 6: China's Super-AAA ("AAA+") Issuers

\begin{tabular}{|cccc|}
\hline "AAA+" Issuers & Chinese Full Name & $\begin{array}{c}\text { International Issuer } \\
\text { Rating } \\
\text { (S\&P/Moody's/Fitch) }\end{array}$ & $\begin{array}{c}\text { Outstanding (in } \\
\text { Billion RMB) }\end{array}$ \\
\hline China Railway Corp & 中国铁路总公司 & NR & $1,610.50$ \\
China National Petroleum Corp & 中国石油天然气集团有限公司 & A+/A1/AA & 239.96 \\
China Petrochemical Group & 中国石油化工股份有限公司 & A+/A1 & 20.00 \\
China National Offshore Oil Corp & 中国海洋石油集团有限公司 & A+/A1 & 10.00 \\
China Telecom Corp & 中国电信股份有限公司 & NR & 28.00 \\
China Unicom Corp & 中国联合网络通信有限公司 & NR & 18.00 \\
China Mobile Group & 中国移动通信集团有限公司 & A+/A1 & - \\
State Grid & 国家电网有限公司 & A+/A1/A & 203.70 \\
China Southern Power Grid & 中国南方电网有限责任公司 & A+/A1/A+ & 92.90 \\
China Three Gorges Corp & 中国长江三峡集团有限公司 & A/A1/A+ & 81.00 \\
\hline
\end{tabular}

Data source: Outstanding numbers are from Wind Database Credit Bond Research.

International Issuer Ratings are from S\&P, Moody’s and Fitch database respectively.

S\&P: https://www.standardandpoors.com/en_US/web/guest/home

Moody's: https://www.moodys.com/

Fitch: https://www.fitchratings.com/site/home

Here we include all bond types along with corporate bonds. This treatment only affects China Railway Corp in a significant way, because some bonds issued by China Railway Corp are categorized as “bonds with government support (政府支持机构 债),” which are under the Government Bond category based on our definition.

Outstanding numbers are calculated as of 12/31/2018. 
Table 7: Top 10 Corporate Issuers in China Onshore Bond Market

\begin{tabular}{|cccc|}
\hline Issuer & $\begin{array}{c}\text { Outstanding } \\
\text { (Billion RMB) }\end{array}$ & $\begin{array}{c}\text { Domestic } \\
\text { Issuer Rating }\end{array}$ & $\begin{array}{c}\text { International Issuer Rating } \\
\text { (S\&P, Moody's, Fitch) }\end{array}$ \\
\hline $\begin{array}{c}\text { China National Petroleum } \\
\text { Corporation } \\
\text { (中石油) }\end{array}$ & 239.96 & AAA & A+/A1/AA \\
$\begin{array}{c}\text { State Grid Corporation of China } \\
\text { (国家电网) }\end{array}$ & 203.70 & AAA & A+/A1/A \\
$\begin{array}{c}\text { Central Huijin Investment } \\
\text { (中央汇金投资) }\end{array}$ & 179.00 & AAA & NR \\
$\begin{array}{c}\text { State Power Investment Corporation } \\
\text { (国家电力投资公司) }\end{array}$ & 132.67 & AAA & A-/A2/A \\
$\begin{array}{c}\text { Tianjin Infrastructure Construction \& } \\
\text { Investment Group } \\
\text { (天津城市基础设施建设投资集团) } \\
\text { China Railway Corp. } \\
\text { (中国铁路总公司) }\end{array}$ & 125.70 & AAA & BBB+/A \\
$\begin{array}{c}\text { Datong Coal Mine Group } \\
\text { (大同煤矿集团) }\end{array}$ & 110.00 & AAA & NR \\
China Southern Power Grid \\
(中国南方电网) \\
$\begin{array}{c}\text { Shougang Group } \\
\text { (首钢集团) }\end{array}$
\end{tabular}

Data source: Outstanding numbers and domestic ratings are from Wind Bond Database.

International Issuer Ratings are from S\&P, Moody’s and Fitch database respectively.

S\&P: https://www.standardandpoors.com/en_US/web/guest/home

Moody's: https://www.moodys.com/

Fitch: https://www.fitchratings.com/site/home

Outstanding numbers are calculated as of 12/31/2018. 
Table 8: Upgrades Dwarf Downgrades in China's Onshore Bond Market

\begin{tabular}{|c|c|c|c|c|c|c|c|c|c|c|}
\hline & \multicolumn{5}{|c|}{ Ratings as of $12 / 31 / 2018$} & \multirow[b]{2}{*}{$\begin{array}{c}\text { \# of } \\
\text { Issuers }\end{array}$} & \multirow[b]{2}{*}{ Upgrades } & \multirow[b]{2}{*}{ Downgrades } & \multirow[b]{2}{*}{ Maintain } \\
\hline & & AAA & AA+ & AA & AA- & $\begin{array}{l}\mathrm{A}+\text { or } \\
\text { below }\end{array}$ & & & & \\
\hline \multirow{5}{*}{ 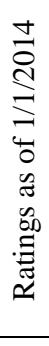 } & AAA & 300 & 4 & 0 & 2 & 0 & 306 & & $1.96 \%$ & $98.04 \%$ \\
\hline & $\mathrm{AA}^{+}$ & 191 & 240 & 17 & 5 & 5 & 458 & $41.70 \%$ & $5.90 \%$ & $52.40 \%$ \\
\hline & AA & 39 & 350 & 736 & 28 & 35 & 1188 & $32.74 \%$ & $5.30 \%$ & $61.95 \%$ \\
\hline & AA- & 2 & 40 & 231 & 253 & 33 & 559 & $48.84 \%$ & $5.90 \%$ & $45.26 \%$ \\
\hline & $\mathrm{A}+$ or below & 0 & 6 & 29 & 30 & 208 & 273 & $23.81 \%$ & & $76.19 \%$ \\
\hline & & 532 & 640 & 1013 & 318 & 281 & & & & \\
\hline
\end{tabular}

Data source: Wind Database

Our rating migration matrix consists only of issuers with ratings on 1/1/2014 and 12/31/2018, excluding not-rated issuers. More specifically, we begin with a full list of corporate bonds that are available on 12/31/2018 with their respective issuer ratings. For each issuer, we then match its ratings on $1 / 1 / 2014$ and 12/31/2018. With the two ratings for each issuer, we assign them to their corresponding cells in the rating migration matrix. 
Table 9: China's Domestic Credit Rating Agencies

\begin{tabular}{|c|c|c|c|c|c|c|c|c|}
\hline \multirow[b]{2}{*}{ Agency } & \multicolumn{2}{|c|}{ Market Share } & \multirow[b]{2}{*}{$\begin{array}{l}\text { Bond } \\
\text { Outstanding } \\
\quad \text { (in \%) }\end{array}$} & \multirow[b]{2}{*}{$\begin{array}{l}\text { Number } \\
\text { of } \\
\text { Issuers } \\
\text { (in \%) }\end{array}$} & \multirow[b]{2}{*}{ NAFMII } & \multirow[b]{2}{*}{ CSRC } & \multirow[b]{2}{*}{ NDRC } & \multirow[b]{2}{*}{ CIRC } \\
\hline & $\begin{array}{c}\text { Bond } \\
\text { Outstanding } \\
\text { (in Billion } \\
\text { RMB) }\end{array}$ & $\begin{array}{l}\text { Number } \\
\text { of } \\
\text { Issuers }\end{array}$ & & & & & & \\
\hline $\begin{array}{c}\text { China Chengxin Securities } \\
\text { Rating } \\
\text { (中诚信证券) }\end{array}$ & $2,496.36$ & 370 & \multirow{2}{*}{$41.35 \%$} & \multirow{2}{*}{$28.73 \%$} & & $x$ & & $x$ \\
\hline $\begin{array}{c}\text { China Chenxin International } \\
\text { Rating } \\
\text { (中诚信国际) }\end{array}$ & $12,548.97$ & 980 & & & $x$ & & $x$ & $x$ \\
\hline $\begin{array}{l}\text { China United Rating } \\
\text { (联合信用) }\end{array}$ & $1,832.19$ & 357 & \multirow{2}{*}{$24.93 \%$} & \multirow{2}{*}{$22.54 \%$} & & $x$ & & $x$ \\
\hline $\begin{array}{l}\text { China Lianhe Rating } \\
\text { (联合资信) }\end{array}$ & $7,237.97$ & 702 & & & $x$ & & $x$ & $x$ \\
\hline $\begin{array}{l}\text { Dagong Global Credit } \\
\text { Rating (大公国际) }\end{array}$ & $3,787.82$ & 482 & $10.41 \%$ & $10.26 \%$ & $x$ & $x$ & $x$ & $x$ \\
\hline $\begin{array}{c}\text { Shanghai Brilliance Credit } \\
\text { Rating } \\
\text { (上海新世纪) }\end{array}$ & $5,176.71$ & 638 & $14.23 \%$ & $13.58 \%$ & $x$ & $x$ & $x$ & $x$ \\
\hline $\begin{array}{c}\text { Pengyuan Credit rating } \\
\text { (鹏元资信) }\end{array}$ & 778.57 & 641 & $2.14 \%$ & $13.64 \%$ & & $x$ & $x$ & $x$ \\
\hline $\begin{array}{c}\text { Golden Credit Rating } \\
\text { (东方金诚) }\end{array}$ & $1,541.38$ & 376 & $4.24 \%$ & $8.00 \%$ & $x$ & $x$ & $x$ & $x$ \\
\hline $\begin{array}{c}\text { China Bond Rating } \\
\text { Corporation (中债资信) }\end{array}$ & 983.73 & 153 & $2.70 \%$ & $3.26 \%$ & & & & \\
\hline Total & $36,383.69$ & 4,699 & $100.00 \%$ & $100.00 \%$ & & & & \\
\hline
\end{tabular}

Data source: Wind Database Credit Bond Research

All numbers are calculated as of 12/31/2018. 


\section{References}

Jennie Bai, and Hao Zhou, 2018, The funding cost of Chinese local government debt. Working paper, George Washington University.

Amihud, Yakov. Illiquidity and stock returns: cross-section and time-series effects. Journal of financial markets 5, no. 1 (2002): 31-56.

Anderson, Mike, and René M. Stulz. Is post-crisis bond liquidity lower?. No. w23317. National Bureau of Economic Research, 2017.

Asian Development Bank, 2012, ASEAN+3 Bond Market Guide, Vol 1. Part 2. PRC Bond Market Guide.

Chen, Hui, Zhuo Chen, Zhiguo He, Jinyu Liu, and Rengmin Xie, 2018, Pledgeability and Asset Prices: Evidence from the Chinese Corporate Bond Markets, working paper, Chicago Booth.

Chen, Zhuo, Zhiguo He, Chun Liu, 2019, The Financing of Local Government in China: Stimulus Loan Wanes and Shadow Banking Waxes, working paper, Chicago Booth.

Ehlers Torsten, Steven Kong, and Feng Zhu, 2018. Mapping shadow banking in China: structure and dynamics, BIS working paper.

Huang, Ji, Zongbo Huang, and Xiang Shao, 2018. The risk of implicit guarantees: evidence from the shadow interbank market in China. Working paper.

Huang, Yi, Ugo Panizza, and Richard Portes, 2018. Corporate foreign bond issuance and interfirm loans in China. Working paper.

Jiang, Xianfeng and Frank Packer, 2017. Credit ratings of domestic and global agencies: What drives the differences in China and how are they priced? BIS working paper.

Kennedy, Scott, 2008. China's Emerging Credit Rating Industry: The Official Foundations of Private Authority. The China Quarterly No. 193 (Mar., 2008), pp. 65-83.

Lei, Katherine, George Cai, Stephen Tsui, Jemmy Huang, Haibin Zhu, Marvin Chen, and Soo Chong Lim, 2018. China financials: embracing a rise in corporate bond defaults, J.P. Morgan Asia Pacific Corporate Research.

Mo, Jingyuan, and Marti Subrahmanyam, 2019, Policy interventions, liquidity, and clientele effects in the Chinese corporate credit bond market, working paper, NYU Stern.

Jin, Shuang, Wei Wang, and Zhang Zilong, 2018. The value and real effects of implicit guarantees. Working paper.

Poon, Winnie and Kam C Chan, 2008. An Empirical Examination of the Informational Content of Credit Ratings in China. Journal of Business Research 61,790-797.

Sun, Guofeng, 2015, Reforms in China’s Monetary Policy: A Frontbencher’s Perspective, Palgrave Macmillan, USA.

Standard Chartered, 2017, Chinas Credit Rating Framework. Global research report. 
Liu, Laura Xiaolei, Yuanzhen Lyu, and Fan Yu, 2017. Implicit Government Guarantee and the Pricing of Chinese LGFV Debt. Working paper.

Wang, Shujing, Kuo-chiang Wei, and Ninghua Zhong, 2015. One Bond, Two Prices: The Demand Effect of Yield-Chasing Retail Investors. Working paper. 